\title{
Migrar, morir y seguir perteneciendo. El Día de los Muertos centroandino del cementerio de Flores de Buenos Aires
}

\section{To migrate, die and keep belonging. The central-Andes Day of the Dead in the Flores Cemetery of Buenos Aires}

\author{
Pablo Mardones $^{1}$ https://orcid.org/0000-0002-4490-1391 \\ ${ }^{1}$ Investigador del Instituto de Estudios Internacionales (INTE) de la Universidad Arturo Prat \\ (UNAP), Iquique, CHILE. Email: mardones.pablo@gmail.com
}

\begin{abstract}
Resumen
Este artículo deriva de una etnografía estratégicamente situada, realizada entre 2008 y 2014, sobre la celebración del Día de Muertos en el cementerio de Flores y barrios del suroeste de Buenos Aires (Argentina). Mi observación etnográfica, además de revisión bibliográfica y de prensa, da cuenta de una dinámica regional latinoamericana en la que en las grandes ciudades de aquellos países cuya identidad estado-nacional es más bien imaginada como "noindia”, se vienen presentando, desde mediados del siglo XX, un declive del festejo del Día de los Muertos. Paralelamente, en aquellos países que incorporan las identidades "indias", la celebración viene en aumento. Esta investigación posiciona a Buenos Aires en ambas esferas: observándose una disminución del festejo local por parte de la población autóctona y el crecimiento de las celebraciones protagonizadas por migrantes aymara, kolla y quechua provenientes de los Andes centrales. A partir de informaciones etnográficas, identifico cómo estas personas radicadas en Buenos Aires generan procesos de comunalización y dinámicas relacionales en la resignificación de la celebración a los difuntos y el entierro de los suyos en este nuevo espacio. Sugiero que en estos procesos los sujetos van construyendo territorialidades y produciendo nuevos sentidos de apego a las localidades de arribo.
\end{abstract}

Palabras claves: Día de Muertos, cementerio de Flores, Andes centrales, comunalización, dinámicas relacionales.

\begin{abstract}
This article is a result of a strategically situated ethnography on the celebration of the Day of the Dead, carried out between 2008 and 2014 at the Cemetery of Flores and in the south-western neighborhoods of Buenos Aires (Argentina). The data gathered through ethnographic observation and a bibliographic and press review show a Latin American regional dynamic in which we observe from the mid-twentieth century a decline of the celebration of the Day of the Dead in the large cities of those countries that have constructed their national-state identity as "non-Indian". At the same time, in those countries that have included "Indian" identities in their national imaginaries, the celebration is increasing. The research carried out positions Buenos Aires in both spheres: while the celebration of this festivity has declined among the native population, it has grown among Aymara, Kolla and Quechua migrants from the central Andes. I identify how these migrants generate processes of communalization and relational dynamics in the resignification of the celebration to the deceased and the burial of their own people in Buenos Aires. I suggest that in these processes, the subjects build territorialities and produce new senses of attachment towards the new spaces they inhabit.
\end{abstract}

Keywords: Day of the Dead, Flores Cemetery, Central Andes, communalization, relational dynamics.

Recibido: 3 enero 2018. Aceptado: 16 abril 2018 


\section{Presentación}

El texto está dividido en tres apartados. En la introducción pongo en circulación algunas ideas y autores, los cuales comprenden la muerte como práctica social y ritual. También delineo algunos aspectos sociopolíticos que interpelan la construcción de estos ritos en Latinoamérica. En el segundo apartado, reviso diferentes etnografías del culto a los muertos realizadas en comunidades rurales de Bolivia. Lo anterior con el propósito de reconstruir un marco interpretativo general para comprender el entramado simbólico que da sentido social a estas prácticas. Si bien el culto a los muertos en la ciudad de Buenos Aires resignifica -desde una perspectiva migratoriaalgunas de estas prácticas, lo hace desde una lógica que actualiza el festejo porteńo como un juego de presuposición y recreación relacionado con las vivencias en origen. En el tercer apartado, me centro en la celebración del rito en Buenos Aires, describiéndolo y analizándolo desde mi experiencia como músico, señalando así las similitudes y diferencias con el rito en las zonas de origen de los migrantes. Finalmente, en el apartado final ofrezco conclusiones analíticas sobre las informaciones etnográficas trabajadas en los apartados anteriores.

\section{Introducción}

La celebración de la muerte confirma un rito extendido en el tiempo y en el espacio. Desde muy tempranamente la ritualidad fúnebre adquirió relevancia en la constitución de los sujetos como seres culturales (Ochoa, 1974; Berg, 1989; Fernández, 1998; López Austin, 1999; Aláez García, 2001; Ferraro, 2004; Kauffman, 2010; Hidalgo, 2011; Fernández y Michel, 2014). La posibilidad de comunicación e intercambio con aquellos que ya no están vivos influencia las maneras de entender la vida y la muerte y, con ello, la posibilidad de agencia de vivos y muertos en sus respectivos territorios.

En Europa, su origen tiene relación con una antigua celebración celta de inicio del invierno, llamada $h a-$ monis, que se realizaba a comienzos de noviembre. El rito fue posteriormente sincretizado por los romanos con la cosecha de la manzana, celebrando a Pomona, diosa de la fruta (Garnier, 1904). En el año 980, con el fin de mantener el dominio espiritual de la Iglesia sobre una práctica profundamente arraigada, el rito fue incorporado al cristianismo por el abad de Corvey (Roger, 2002). En los Andes centrales, como denotan las crónicas de Guaman Poma de Ayala (1980 [1615]) sobre los incas, esta festividad -al igual que en Europa- coincidía con el actual principio de noviembre. Aunque no encontré investigaciones que desarrollaran esta semejanza, dicha coincidencia sugiere un fenómeno astronómico análogo en ambos hemisferios interpretado de forma similar.

En América, actualmente la importancia de la conmemoración a la muerte en la región se evidencia en el calendario oficial de la mayoría de los Estadonaciones. Salvo algunas excepciones, este es un día feriado en el continente. ${ }^{1}$ En los países donde la relevancia cuantitativa (por autoadscripción censal) y cualitativa de los pueblos amerindios ha sido históricamente reducida o comprimida, la preeminencia de este festejo fue ejercida desde el cristianismo, como en Argentina, Chile, Brasil o Uruguay. Mención aparte tiene el Halloween celebrado en Canadá y Estados Unidos, culto que responde a la tradición celta del all hallows' eve (víspera de todos los santos) traída desde el norte europeo (Roger, 2002). En aquellos países donde los pueblos indígenas son relevantes porcentual, social y políticamente -como Bolivia, Ecuador, Guatemala, México y Perú-, la celebración hacia y con los muertos se presenta de una forma sincrética entre los usos y prácticas amerindios y cristianos. En todos los países donde se conmemora, el rito es celebrado en la misma época: entre fines de octubre y principios de noviembre.

En el caso del primer grupo de países, el festejo a los muertos ha ido declinando desde la segunda mitad del siglo XX, disminuyendo ostensiblemente el público que visita los cementerios a principios de noviembre. Pero en algunos de ellos la celebración se revitalizó en las últimas décadas debido a los migrantes de países con mayor relevancia indígena y sus hijos y nietos nacidos en destino. Así, el rito comenzó

1 En Sudamérica, con excepción de Argentina, Paraguay, Venezuela. En ciertos países, como Chile, Colombia, Guatemala, Perú, es feriado el 1 de noviembre, "Día de Todos los Santos”. En Bolivia, Brasil, Ecuador, México y Uruguay, es el 2: "Día de los Difuntos”. En otros países, la celebración está sujeta a movilidad. 
a rehabilitar el espacio del cementerio para celebrar de forma masiva el culto a los ancestros. Este es el caso de los migrantes del centro-sur de México en los Estados Unidos y de los migrantes proveniente de los Andes centrales, en Buenos Aires. ${ }^{2}$

En la actualidad bajó mucho la afluencia, especialmente en Chacarita, ya que en Recoleta nunca fue muy multitudinario. En Flores, donde hay una importante presencia de la comunidad boliviana, volvió a ir mucha gente, cuenta Néstor Pan, a cargo de la Dirección General de Cementerios, y recuerda: En Chacarita, hasta hace 30 años se superaban las 200 mil personas, se prohibía el ingreso de coches, pero eso ya no pasa ahora. Viene más gente que en cualquier otro día, pero nada que ver (Clemente, 2011).

En los países en que estos ritos adquirieron carácter estado-nacional como consecuencia de su oficialización, las prácticas amerindias de culto a los muertos se masificaron. En las calles y cementerios de las principales ciudades de Bolivia, Ecuador, Guatemala o México es imposible transitar por estas fechas, lo que denota una profunda y copiosa apropiación del espacio público. Los gobiernos incluso prevén la intervención de las fuerzas de seguridad para organizar las multitudes y evitar disturbios. Dichas aglomeraciones también ocurren en algunos cementerios populares de las urbes que comenzaron a recibir migración amerindia -tanto interna como internacional-, casos en los que, en general, se busca restringir y controlar ciertas costumbres. Son sobresalientes aquellas relacionadas a la expresión musical y el consumo de alcohol.

Así expresaba una nota del periódico El Deber de Santa Cruz (Bolivia), y otra del diario La Nación (Argentina):

2 Particularmente, el cementerio de Flores de la ciudad de Buenos Aires y, en menor medida, otros de la provincia de Buenos Aires y de otras ciudades argentinas. Por su parte, según lo que me contó en conversaciones Ruth Camacho (10 de junio, 2013), migrante boliviana radicada hace más de 20 años en São Paulo (Brasil), cada vez más familias empiezan a rendir homenaje a sus muertos en algunos cementerios de la zona este de la metrópolis en esta fecha.
La modalidad de control es la misma, pero el alcance esta vez, lo anuncian, será mayor. La Oficialía Mayor de Defensa Ciudadana tiene un plan de seguridad que incluye la movilización de 300 guardias municipales hacia los camposantos de su jurisdicción durante la celebración del Día de los Difuntos. El propósito es repeler el consumo de bebidas alcohólicas al interior de los cementerios, así como evitar el ingreso de bandas de música o que se produzcan disturbios (El Deber, edición virtual, 12 de octubre 2012).

Familias enteras con platos típicos, música $\mathrm{y}$ ofrendas florales se acercaron desde temprano por los accesos de la calle Varela y Balbastro. Allí la Gendarmería Nacional y la Policía Metropolitana habían montado un operativo de control e impedían el ingreso de bebidas alcohólicas, entre otras cosas (La Nación, edición impresa, 3 de noviembre 2013).

Ya sea como efecto de la oficialización del Día de los Difuntos en algunos países, o como resultado de la migración en otros, el encuentro de miles de personas en los cementerios devino un evento masivo, extendido y visible en gran parte de Latinoamérica.

En la ciudad de Buenos Aires, el Día de los Difuntos -nombrado en quechua como aya markay quilla o Wiñay Pacha, en aymara- es celebrado por migrantes del área andina central, principalmente del occidente boliviano, del Noroeste Argentino (NOA) y sureste peruano, así como sus herederos porteños. ${ }^{3}$ Actualmente, dicha fecha representa uno de los rituales más significativos en el proceso de aymarización y quechuización experimentado en la metrópolis (Mardones, 2016) (Figura 1).

Desde hace una década, su celebración es masiva en el cementerio de Flores de la ciudad de Buenos Aires. Concurren muchísimas familias -a pesar de no ser día feriado en Argentina-, congregando a varios miles de personas.

3 Porteńo es el gentilicio de los oriundos de la ciudad de Buenos Aires. 


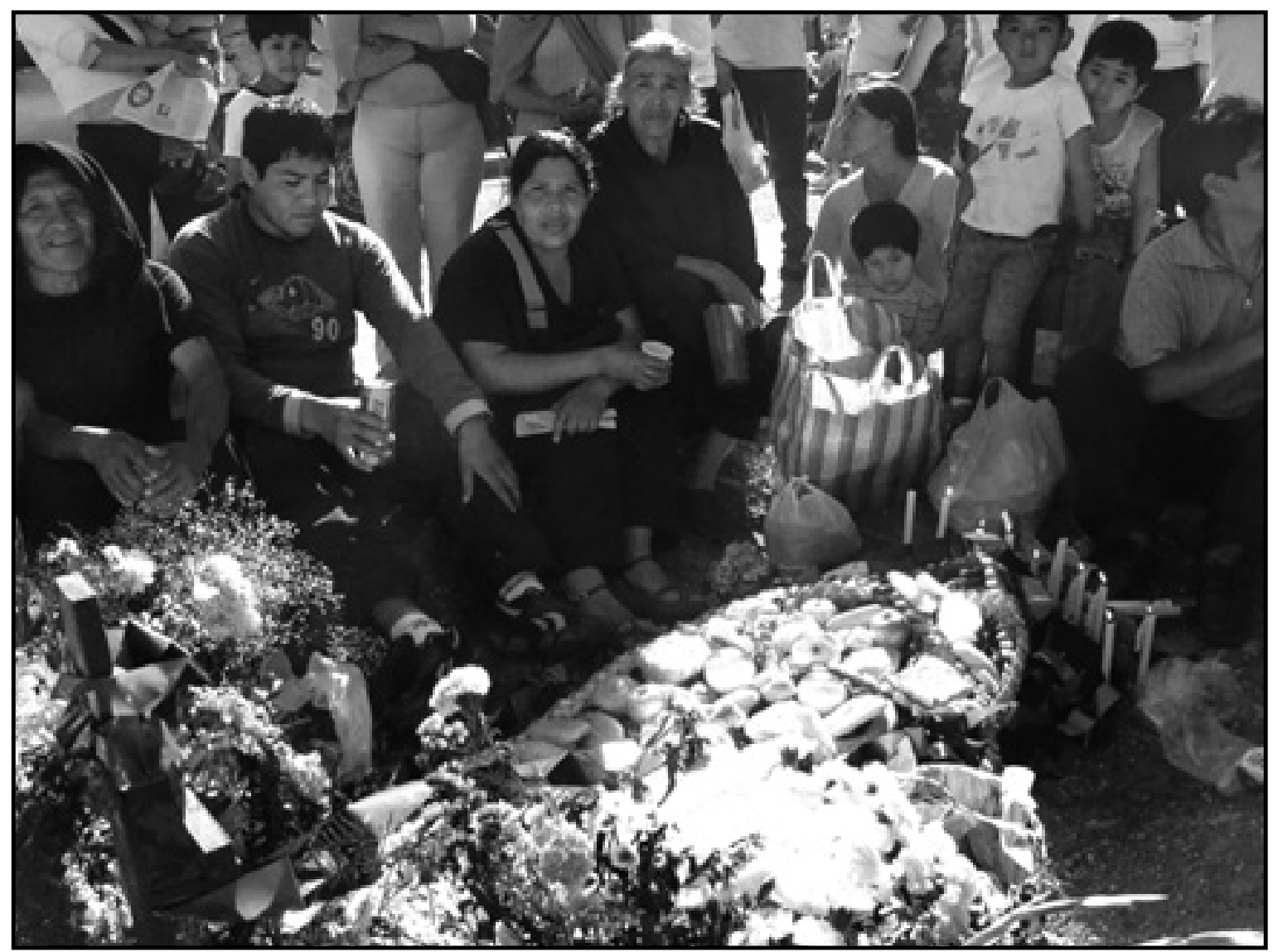

Figura 1. Cementerio de Flores. Registro: Periódico Renacer. 2 de noviembre de 2008. Buenos Aires, Argentina.

Un clima festivo, podría decirse, invadió ayer el cementerio de Flores. La celebración del Día de los Muertos -o de los Fieles Difuntos, para el culto católico- por parte de la comunidad boliviana transformó la imagen del predio. Más de diez mil personas rezaron, cantaron y homenajearon a sus difuntos, respetando una milenaria tradición del altiplano (Diario La Nación, edición impresa, 3 de noviembre 2013).

Pero ¿qué dinámicas deben afrontar los migrantes aymara, kolla y quechua ${ }^{4}$ para trasladar un rito que,

4 Se trata de tres pueblos que, históricamente, habitaron los Andes centrales. Conforman, junto a otros grupos, un complejo de prácticas, costumbres y formas de organización social que los emparenta. Comparten una articulación cultural que es genéricamente denominada como "cultura andina". En el caso de los migran- en su cosmogonía, está sujeto a sus territorialidades? ¿Qué implica enterrar a sus muertos en un lugar lejano? ¿Cómo se ha reconfigurado el territorio social urbano ante la masificación del Día de los Difuntos en el cementerio de Flores?

Como hipótesis, planteo que la muerte de migrantes, su entierro y consecuente resignificación de los

tes amerindios en Buenos Aires, un grupo importante proviene de la Provincia de Jujuy, norte argentino, y se adscriben mayoritariamente como kolla. No hay claridad respecto al actual pueblo o cultura kolla (también escrito colla, coya o qolla). Por un lado, puede tratarse de descendientes del señorío kolla de origen aymara; por otro, respondería a una categoría inca para denominar a los pueblos al sur del imperio Tawantisuyo: el Kollasuyo (parcialidad del sur) (Rostworowski, 1988). Hay poblaciones que se reivindican como kolla en Argentina, Bolivia y Chile. 
ritos fúnebres centroandinos 5 genera sentidos de comunalización. Esta es entendida, siguiendo a Brow (1990), como cualquier patrón de comportamiento de promoción de un sentido de pertenencia y de dinámicas relacionales (Carsten, 2000). Remite a la necesidad que sienten los grupos sociales -más allá del parentesco consanguíneo- de crear vínculos y relacionarse entre sí a través de maneras particulares y creativas.

Me propuse describir y analizar estos eventos en Buenos Aires, a partir de una investigación antropológica realizada entre 2008 y 2014. En ella, llevé a cabo una "etnografía estratégicamente situada" (Marcus, 1995) en la que participé del festejo el 1 de noviembre en el ámbito privado y el 2 de noviembre en el cementerio de Flores. Las informaciones etnográficas fueron complementadas con entrevistas en profundidad realizadas entre 2009 y 2011, algunas de las cuales formaron parte de la película documental Tantawawas. Memoria del Indoamericano (2012) que produje junto a Guillermo Mamani y Nicolás García Recoaro.

\section{La celebración aymara-quechua}

En el período prehispánico, el culto a los muertos en los Andes centrales formaba parte de un sistema de creencias. En esta celebración, el espacio físico y social constituían un todo (Ochoa, 1974; Berg, 1989; Aláez García, 2001). En ocasiones, los difuntos eran enterrados junto a las viviendas de los vivos, manteniéndose ligados a ellos cotidianamente (Machicao Arauco, 2009). En otras, eran sepultados en las wak'as, donde se rendía culto a los antepasados (Rivera-Cusicanqui, 2010).

Las investigaciones arqueológicas, etnohistóricas y etnográficas coinciden en que la celebración de este

5 El concepto "andino", surgido del diálogo entre escritores indigenistas y antropólogos andinistas en la segunda mitad del siglo XX (Salomon, 1982), es insuficiente para hablar de lógicas propias de los Andes centrales. Se suele comprender a "lo andino" como a la cultura del altiplano boliviano-peruano y sus zonas de influencia, obviando a los habitantes de otras regiones de esta cordillera. En atención a esto, en este trabajo me referiré a centroandino o Andes centrales para hablar de esta población. rito ancestral alcanzó un carácter de especial relevancia entre los pueblos centroandinos ${ }^{6}$ (Kauffman, 2010), perdurable hasta la actualidad. Por ello, la conmemoración fue extensamente trabajada por diversos etnógrafos (Ochoa, 1974; Rivera Cusicanqui, 1984; Berg, 1989; Fernández, 1998; Aláez García, 2001).

Los grupos culturales y las familias que participan de esta festividad, en Buenos Aires, reconstruyen un culto a los muertos, tanto presuponiendo formas $y$ contenidos heredados de sus ancestros o experimentados por ellos en los Andes centrales -siempre en articulación con formas y contenidos de la tradición cristiana- como recreando sus sentidos en destino. La transmisión de saberes se operacionaliza en una "zona de contacto" (Pratt, 1992): 7 las personas citan un origen que presuponen, pero, simultáneamente, crean y producen nuevos conocimientos en las zonas hacia donde migran.

Según Bastien (1996), el rito a los muertos representa en el calendario centroandino el paso de la estación seca a la estación húmeda. Simboliza, además, el traslado de las actividades de los vivos a las de los muertos, con la visita de los últimos a los primeros.

El 1 de noviembre, sobre el mediodía, comienza la fiesta. Se construye una apxäta (tumba o casa del muerto $)^{8}$, más común en el ámbito rural, o un altar doméstico preponderante en pueblos grandes o ciudades. Esta estructura servirá como espacio de asamblea y reunión de las "almas", a semejanza de lo que sucede en las reuniones y asambleas comunitarias, protagonizadas por los vivos (Fernández, 1998).

6 Pese a que la mayor parte de la bibliografía es referida a la celebración de comunidades aymara, debido a que los pueblos de los Andes centrales conforman un complejo de prácticas que los emparenta, estas son asimilables a la celebración quechua, kolla y de otros pueblos de la denominada "cultura andina".

7 Pratt se refiere a "zonas de contacto" para definir aquello lugares en los que confluyen culturas con trayectorias históricamente divergentes, frecuentemente atravesadas por relaciones coloniales.

8 Apxäta es una estructura formada por cañas dulces en forma de trípode en la cual se afirman las hojas superiores al tablón o mesa que sirve de base (Fernández, 1998). 
Ahí los difuntos se reunirán reposando de su largo viaje, recibirán las visitas de aquellos que están en condiciones de comunicarse con ellos, unos a través de la música, otros -los resiris (rezadores) - a través de oraciones y plegarias.

El altar doméstico está cubierto con un mantel o una sábana (negra o morada, cuando el difunto es adulto, y blanca, cuando es niño o joven) que tiene dos o a veces tres niveles (simbolizando la cosmovisión centroandina). La forma más sencilla es una mesa pequeña sobre una más grande y, en algunos casos, sobre una tercera. Se cubren las dos o tres mesas con los manteles o sábanas, colocándose todas las cosas que se quiere ofrecer al difunto. En los dos primeros niveles ${ }^{9}$, además de la fotografía del difunto, se colocan velas encendidas, objetos sagrados, algo suyo y los panes en forma de escalera, símbolos estelares $\mathrm{y}$ animales. En el nivel inferior, ${ }^{10}$ el más importante, llamado la mesa del difunto, se colocan alimentos y bebidas que se han preparado para su "alma".

El primer protagonista que aparece concentrando el interés, esfuerzo y capital de la comunidad es el t'anta (pan), que representa el "alma" del difunto. Actualmente, se les pone una careta de yeso que simboliza su rostro. El predominante es el tantawawas (pan de bebé), aunque también, con menor predominancia, se hacen t'antaachachis (abuelos) y, excepcionalmente, t’antaawilas (abuela) (Fernández, 1998). Además de estas figuras humanas, se hacen soles, estrellas, lunas, cruces, caballos y/o llamas, ${ }^{11}$ para que las "almas" se transporten de ida y regreso al wiñay marka (pueblo o ciudad eterna).

En la mañana del 2 de noviembre, las "almas" se trasladan al cementerio para unirse por unas horas con sus cadáveres que yacen en los sepulcros (Albó, 1974, en Berg, 1989). Los familiares trasladan al cementerio en un kepi (bulto), los elementos de las apxätas o altares -que el día anterior construyeron en sus casas y que desmantelaron en la mañanapara reconstruirlas encima de los sepulcros. Ahí se colocará comida para los nuevos visitantes que serán

9 Adquieren simbología el hanan o alak pacha y el aka pacha (en quechua y aymara respectivamente).

10 La simbolización aquí está dada por el urin o manka pacha.

11 A veces también perros y ovejas. muchos más que los que visitaron al "alma" el día anterior (Fernández, 1998).

En el cementerio se repite, prácticamente, todo lo hecho en las casas desde el momento de la llegada de las "almas" hasta el amanecer. No debe regresar ninguna comida de vuelta a casa: de lo contrario las penas volverán al hogar.

En algunos lugares, como es el caso de la comunidad de Toke Pucuro en la Provincia Omasuyos del Departamento de La Paz, donde participé de la fiesta en 2019, la fiesta de muertos continúa hasta el día 3 de noviembre (Fernández, 1998). Particularidad también de esta zona es la interpretación del muqunis (también conocido como alma pinkillo),${ }^{12}$ música que solo se interpreta en esta época, para luego ser ofrendada a los muertos.

El baile y el gozo por la despedida de las "almas" durarán toda la noche, amaneciendo los festejantes completamente ebrios. Así lo demanda la cortesía para con sus difuntos. Al día siguiente, los objetos que estaban depositados en la apxäta retornarán a su condición profana anterior, con posibilidad de ser comidos. Lo mismo sucede con el pan, el cual recién al secarse y hacerse duro (cuando el "alma" lo abandona) podrá ingerirse, convirtiéndose en alimento, en sustento de vida (Ferraro, 2004).

La bibliografía etnográfica sobre el rito de la muerte en los Andes centrales permite configurar tres elementos simbólicos centrales que lo estructuran y que detallaré a continuación.

\section{El muerto sigue perteneciendo}

En los Andes centrales la muerte no es un tabú. Morir no genera frustración o rechazo, no se disimula el

12 El término muquni, es "derivado de muqu, 'codo' y 'petiso' [...] presenta un nudo, una falla o 'giba' que le otorga, precisamente, su notoriedad. En esa 'imperfección' o rugosidad, frente al rectilíneo wayru (pinquillo de carnaval), estriba su pertinencia en relación con el dominio ceremonial de las 'almas', otorgándole peculiares virtudes en relación con el timbre del instrumento. No tiene sentido tocar el muquni en ninguna otra ocasión a lo largo del año y a nadie se le ocurriría hacerlo fuera de la fecha" (Fernández, 1998, pp. 152-153). 
hecho de fallecer ni el lugar de entierro, ni provoca repulsión el cadáver. En palabras de Aláez García, "hay momentos durante el ańo que es necesario estar con los finados para que estos sigan siendo protectores de sus deudos" (2001, p. 2).

Hidalgo (2011) plantea que la muerte, por su valor central en la formación de conciencia social, constituye un fenómeno privilegiado de las representaciones colectivas. Aun cuando representa un cambio individual, implica también una modificación en la actitud de toda la comunidad.

Las "almas"13 forman parte de la comunidad de los vivos y pueden intervenir positivamente en favor de los suyos, garantizándoles prosperidad y bienestar (Berg, 1989). Así, las dinámicas relacionales y de comunalización incorporan la interrelación entre vivos y muertos. Los últimos tienen agencia en el mundo de los primeros. Los vínculos relacionales no se pierden cuando unos mueren, ya que los muertos siguen perteneciendo a la comunidad a su vez que continúan teniendo compromisos sociales con esta. $\mathrm{Al}$ ser parte de una misma comunalización, orientada por iguales sentidos de pertenencia, los muertos no pueden desvincularse de la comunidad. Se puede morir, pero no por ello dejar los compromisos vinculantes.

Es solamente después de tres años que se permite que el difunto se descomunalice. Comenzará, entonces, a reconstruir una nueva comunalización que lo llevará a establecer una nueva relacionalidad con la comunidad: "Los muertos participan así en la construcción de una sociedad civil sui géneris, una civilidad ritual que incorpora la mirada y las historias de los difuntos a la normativa y la ética del hacer social que regirá la conducta cotidiana por el resto del año" (Rivera-Cusicanqui, 2010, p. 146).

\section{La época femenina y húmeda}

El Día de los Muertos da inicio a la temporada húmeda en los Andes centrales, espacio geográfico

13 Kauffman (2010), basándose en referencias etnohistóricas, plantea que el concepto "alma", como se conoce en el sentido bíblico, no tuvo vigencia en los Andes centrales. Por ello me referiré a "alma" entre comillas. donde el agua y la humedad son siempre una necesidad constante y dramática. Los difuntos juegan un papel fundamental en el retorno cíclico de las lluvias y la fertilización de la tierra (Saignes, 1993). El entierro humano es tratado, en sí, como un tipo de siembra (Ferraro, 2004). Su retorno, justamente, resulta cíclico, traen la lluvia necesaria para hacer crecer los cultivos, sin los cuales no habría vida (Fernández, 1998).

La caída de la lluvia representa, en los Andes centrales lo femenino, a la mujer preñada (Saignes, 1993). La lluvia significa la fecundación de la tierra que permitirá que prospere la siembra y que crezcan los pastos que alimentarán a los animales. En esta época, la tierra se abre -fenómeno conocido como jallapacha- para recibir las semillas que se transformarán en diversos vegetales y frutos, tal como se concibe que lo hace el espermatozoide al fecundar el óvulo. La tierra es la mujer que crea la vida y las "almas" se presentan en figuras de bebé y en formas de ancianos, representando los dos vértices del ciclo de la vida y la muerte.

\section{La liminalidad del difunto}

Van Gennep (1960) distinguió diferentes fases en los rituales mortuorios, en tanto ritos de pasaje. La persona atravesaría cambios de lugar, estado y posición social en tres etapas sucesivas: rituales de separación (ritos preliminales), de transición (ritos liminales) y de agregación (ritos posliminales). En el transcurso de este pasaje, la persona que se separa de un grupo determinado debe entrar, esperar y salir del período de transición para luego ser incorporado a otro grupo (teóricamente es necesario que se den todas estas etapas). Van Gennep fue quien acunó el concepto de liminalidad ${ }^{14}$ que, retomado por Carsten (2000), alude al estado de apertura y ambigüedad que caracteriza a la fase intermedia de un tiempo-espacio tripartito.

Durante la fase liminal, los sujetos rituales no están ni vivos ni muertos, pero también están vivos y muertos. Durante los tres primeros años, la comunidad no trata a sus muertos como tales, ya que los alimenta, les da de beber y los hace gozar de la música y de la

14 De limen (umbral en latín). 
fiesta. Sin embargo, tampoco son tratados como los vivos (Fernández, 1998), puesto que están en una etapa de transición.

Es similar a lo que sucede con los toraya de Indonesia, quienes mantienen el cuerpo del difunto "durmiendo" hasta que este lo "abandona" (Barley, 2000). Los pueblos de los Andes centrales consideran que, durante estos ańos, el "alma" se encuentra en un período liminal debiendo ser protegida y alimentada hasta que se complete el ciclo ritual para, finalmente, irse a la eternidad. Es un compromiso honrar al difunto con especiales muestras de cariño (Berg, 1989). Se trata de un "alma nueva" (machaqani) y debe ser agasajada por sus familiares durante los tres ańos siguientes a su muerte.

Sin pretensión de homogenizar ni simplificar los procesos en marcha de producción de conocimientos, estas ideas generales me permitieron identificar, por comparación de contextos, algunas interrogantes a poner en juego en mi investigación: ¿Qué es lo que acontece con las personas cuando mueren en un sitio ajeno al que nacieron? En tales circunstancias, ¿ellos retornarían a su comunidad de origen o se quedarían donde han fallecido? ¿Podrían viajar desde Buenos Aires a sus comunidades de los Andes centrales una vez que fallecieron? Me interesa comprender cómo, a partir de estos viajes y retornos de los muertos, se practica el espacio -entendido como un cruce de movilidades que, justamente, lo constituyen (De Certeau, 2000) - en el cual se construye territorialidad (Giménez, 2001), produciéndose nuevos sentidos de memoria y pertenencia en destino.

Retomando lo visto hasta aquí, las ideas centrales del culto y festejo a los muertos en los Andes centrales estarían determinadas por el ciclo agrícola. De esta forma, al igual que las lluvias, los difuntos (a través de sus "almas") retornan cíclicamente, cada ańo. Su llegada, por un lado, marca el final de la temporada seca de los vivos y la época masculina y, por el otro, el inicio de la húmeda, de los muertos y la femenina. Para quienes habitan en zonas rurales, resulta inconcebible realizar esta celebración en otra fecha. El momento del año en el cual se realiza es, en sí, un eje de interpretación, uno en el que se condensan los sentidos de una "renovación".
En la concepción sobre el paso de la vida a la muerte, la idea de "transición" resulta nuclear. Las experiencias de los pueblos de los Andes centrales objetivan, en el período liminal de tres años y en sus prácticas de duelo escalonado, esta etapa de transición en que los difuntos están simultáneamente vivos y muertos y son tratados como tales por la comunidad.

La asociación de la visita de las "almas" de los muertos con el inicio de la temporada femenina presupone una forma de ver el mundo. Una, en la cual las lluvias traídas por las "almas" fertilizan la tierra como lo hace la mujer que engendra, permitiendo la generación de alimentos necesarios para la vida.

En la comida ritual también se inscriben concepciones de mundo. Al adquirir las formas de t'antawawas (panes de bebé) o, en ocasiones, de t'antaachachis (panes de abuelo), el ciclo de la vida y la muerte se ve representado tanto a través de las etapas y parentescos extremos de la vida (bebés y ancianos) como en la asociación entre los panes, las "almas" de los difuntos y sus sentidos simbólicos de fertilidad.

Entre las ofrendas de comida, además del t'anta, el protagonista es el plato que más le gusta al difunto. Asimismo, en la ofrenda hay hoja de coca, alcohol y cigarrillos. A través de los alimentos, las personas vivas materializan el modo específico de entender el pasaje a la muerte, puesto que al agasajar y proveer con comida al "alma" del difunto, ellas se vinculan al compromiso de apoyarlo en su liminalidad para que pueda emprender su viaje.

La relación ritual con el alcohol es muy relevante, y es fundamental para entrar en comunicación con los difuntos y, a través de ellos, con la tierra, antepasados, espíritus y dioses, principalmente los de la fecundidad (Saignes, 1993). El alcohol tiene la función fáctica de abrir los canales de comunicación, constituyéndose como medio idóneo para establecer vínculos entre agencias que operan en planos diferentes.

En general, en los Andes centrales el alcohol más que un uso doméstico (asociado al deguste y acompańamiento de comidas) tiene un rol ritual, operando como un "lubricante social". La forma de ingerirlo, colectivamente, produce sentidos específicos. 
La práctica social de tomar en grandes cantidades, de forma frecuente e, idealmente, hasta llegar a la inconsciencia, es una declaración de confianza en la comunión con las "almas". Mejor aún si dicha embriaguez es colectiva, ya que simboliza la afirmación de un espíritu comunitario entre vivos y muertos (Machicao-Arauco, 2009).

Así, la permanencia en la comunalidad del muerto adquiere una centralidad simbólica en la celebración. El hecho de que la muerte no separe a los difuntos de la comunidad y no implique un corte con los lazos de pertenencia presupone que ellos continúan teniendo responsabilidades y compromisos vinculares con los vivos. Las distintas concepciones sobre la muerte entre los pueblos de los Andes centrales coinciden en pensar este pasaje -de la vida a la muerte- como reafirmación del proceso de comunalización y relacionalidad. Los muertos continúan siendo agentes en el mundo de los vivos. Paralelamente, a través del rol y compromiso de la familia ritual (comadres/compadres y madrinas/padrinos) con la familia de los difuntos, los criterios de "familiarización” no solo incorporan a los muertos: también generan lazos no consanguíneos de parentesco. El festejo de los difuntos a través del lenguaje parental es también una instancia metadiscursiva privilegiada para repensar colectivamente la experiencia de estar reunidos (Ferraro, 2004). Desde esta perspectiva, el ritual de los difuntos es una negociación del "estar juntos" (Massey, 1992), puesto que allí se recrean y confirman los lazos entre los muertos y los vivos, incluyendo parientes, amigos y vecinos.

\section{La celebración del rito mortuorio en la ciudad de Buenos Aires}

Este apartado lo dedicaré a describir y analizar cómo migrantes de la región de los Andes centrales llevan a cabo esta celebración en el cementerio de Flores de la ciudad de Buenos Aires. Aquí retomo las preguntas que he ido planteando con respecto a los efectos simbólicos y políticos que conlleva para estas familias enterrar a sus difuntos lejos del origen, así como las implicancias de la apropiación y masificación del cementerio de Flores por parte de la comunidad centroandina y las tensiones entre dicho rito y el porteño. En síntesis, cómo al practicar la muerte en forma de viajes y retornos de las "almas", se construye territorialidad, entendida como el espacio que estos migrantes valorizan para asegurar la reproducción de sus prácticas vitales (Giménez, 2001) generando novedosos sentidos de apego en el lugar de destino.

Mis nociones sobre esta festividad en Buenos Aires se remiten a siete años continuos de visita al cementerio de Flores el día 2 de noviembre (2008, 2009, 2010, 2011, 2012, 2013 y 2014), en las cuales hice observación directa con registro de fotografía y video y observación participante como músico, además de entrevistas. Entre 2008 y 2010 participé tocando en el Centro Cultural Autóctono Wayna Marka ${ }^{15}$ y, en 2016, con Lakitas del Oriente, ${ }^{16}$ integrado por personas de ciudades de Argentina y Chile sin vinculación con pueblos indígenas de los Andes centrales.

Además, consta del trabajo de campo realizado con algunas familias que me permitieron compartir con ellas el día 1 de noviembre (2009 y 2011) en sus casas. Por su parte, estas nociones también las fui construyendo a partir de mis lecturas académicas realizadas por los pocos investigadores que han trabajado y escrito sobre el tema en Buenos Aires (Canelo y Vargas, 2001; Vargas, 2005; Canelo, 2006; 2010 ; 2013), como así también del material periodístico del que fuese durante más de una década el principal medio de prensa de la comunidad boliviana en Buenos Aires, el periódico Renacer.

En el suroeste de la ciudad de Buenos Aires y el cementerio de Flores, este rito es festejado principalmente por parte de la colectividad boliviana y, en menor medida, por algunas familias peruanas y del NOA, principalmente jujeñas, así como sus hijos y nietos nacidos en esta metrópolis. Dentro del heterogéneo universo de la migración boliviana, sin ser ignorado su trasfondo amerindio, esta festividad goza de un fuerte imaginario etno-nacional, conocida

15 Agrupación fundada por aymara del Departamento de La Paz radicados en la ciudad de Buenos Aires desde la década del ochenta. Realiza diversos ritmos y géneros de los Andes centrales.

16 Las comparsas de lakitas son agrupaciones de zampoñas o lakitas propias del actual Norte Grande de Chile. Lakitas del Oriente es el primer conjunto de lakitas creado fuera de Chile. 
como "fiesta de los bolivianos". Esta prominente bolivianidad trasciende la propia geografía del país, reuniendo en este festejo, entre otras, a la colectividad cochabambina, potosina, orureña, hasta la menos antigua paceña. Además, en menor medida, puneńos (Perú) y jujeños y otros nordesteńos argentinos.

En general, priman los nombres en español y es difícil, aunque existen casos, que den título a la festividad por sus nombres quechua o aymara, como Aya Markay Quilla o Winay Pacha. ${ }^{17}$

El festejo de migrantes del área de los Andes centrales en el cementerio de Flores tiene varias décadas, volviéndose -según lo que me cuenta Jorge Vargas (2014) ${ }^{18}$ masiva y práctica comunitaria en el segundo lustro de la década del noventa, cuando este colectivo comenzó a desplegar uno de los principales procesos de apropiación pública indígena que esta ciudad haya conocido. Según su explicación, este cambio respondería, en gran medida, a la consolidación y fallecimiento de familiares, principalmente aymara, desde Bolivia.

En Buenos Aires, tal como Ferraro (2004) identifica para la sierra ecuatoriana, la agricultura sigue operando como punto de referencia para todas las actividades y celebraciones de la colectividad, esto a pesar de que la mayoría de los migrantes de los Andes centrales no son campesinos (algunos nunca lo fueron, otros dejaron de serlo al migrar). Aun así y, a diferencia de lo que sucede en las comunidades rurales centro-andinas, en Buenos Aires la relación entre el culto a las y los difuntos y la agricultura carece del mismo nexo. Por consiguiente, las prácticas rituales no suelen reponer el mismo metadiscurso que en los lugares de origen en torno a los vínculos entre los muertos, la fertilidad y la regeneración de la vida.

En Buenos Aires, la festividad del Día de los Difuntos está moldeada por las dinámicas socioeconómicas y culturales que los migrantes van incorporando

17 En aymara también hay otros como Almanakan Urupa o Jiwirinakan Urupa, entre otros.

18 Nacido en Cochabamba y radicado en el barrio Charrúa de la ciudad de Buenos Aires, investigador y miembro de la cooperativa Copamuco Ltda. y del Canal 31 de la Villa 31. en la urbe. A diferencia de otras fiestas, como por ejemplo la del Inti Raymi - Machaq Mara, la cual fue reprimida y prohibida y a lo largo del tiempo sincretizada y subsumida en la celebración de Corpus Christi y/o San Juan, el festejo de los muertos, también institucionalizado por la Iglesia católica, conquistó una relevancia estadonacional. Estas articulaciones entre distintos marcos de interpretación sobre la muerte -amerindios, cristianos y estadonacionales- resultó en un complejo simbólico de usos, prácticas y significados que, al mismo tiempo, fue generando sus propios procesos de producción de conocimiento, de acuerdo con los distintos contextos en los que se fue realizando.

\section{Los nuevos muertos migrantes}

Son muchas las similitudes de la festividad de los muertos en el cementerio de Flores con las festejadas en los lugares de origen de los migrantes que las practican, resultando complejo conocer los usos propios de comunidades rurales, tanto del altiplano andino o de las áreas vallunas así como de los centros urbanos (Cochabamba, El Alto, La Paz, Oruro, Potosí, Puno, San Salvador de Jujuy, Tucumán, entre otros), de donde provienen los migrantes de los Andes centrales y zonas aledańas.

Para que la celebración del Día de los Muertos en Flores sea relevante en el espacio privado, así como masiva en el público, operaron heterogéneas redes de tradición y memoria. Fueron las personas pertenecientes a hogares donde cotidianamente se continuaron actualizando las prácticas heredadas de sus antepasados (o se negaron menos), sumado a la preeminencia de los migrantes más memoriosos y/o aquellos de reciente arribo, particularmente aymara, quienes -trasmitiendo conocimientos, quehaceres y usos- revitalizaron la tradicionalidad de ciertos ritos y, conjuntamente, su universo cosmovisionario. Según Jorge Vargas (2014), "la forma aymara implica una relación mucho más colectiva que implica tomar espacios [...] con su llegada se comienza a ver mucha más presencia en espacios públicos" (Entrevista a Jorge Vargas. Buenos Aires, 14.08.2014. Notas del diario de campo).

Desde mediados de la década del ochenta, particularmente a partir del Decreto 21.060 (1985) que en Bolivia propició, entre otras cosas, el cierre de las 
minas y una apertura indiscriminada al comercio exterior que estranguló a la economía campesina (Urioste, 2004), se generó una masiva emigración de aymara dentro y fuera de Bolivia. Este flujo, hasta ese entonces no preponderante en Buenos Aires, tuvo una incidencia particularmente relevante en esta metrópolis. De esta forma, con la llegada masiva de aymara, así como de nuevos migrantes de regiones quechuahablantes, se consolidarán ciertas prácticas de forma comunitaria, entre ellas la masiva celebración del 2 de noviembre en el cementerio de Flores (Mardones, 2016).

Comprendiendo que la memoria social de este festejo se ha conformado a través de disputas y consensos con los variopintos orígenes y épocas desde y cuando han llegado estos migrantes, con apoyo en la vasta bibliografía sobre el rito en el altiplano andino, he tratado aquí de cotejar, comparar y contrastar costumbres de allá y acá con el fin de comprender los sentidos sociales de esta festividad.

En el porteño cementerio de Flores, esta celebración es mucho más corta, es decir, son más acotados los tiempos rituales. Además, hay varios elementos y usos que, al menos hasta ahora, no aparecen. Los horarios del cementerio como espacio público, la implicancia que se trate de un día no feriado y los condicionamientos laborales y de traslado son los principales responsables de las limitaciones temporales del festejo en cuestión. Por otra parte, la reciente -al menos de forma masiva- incorporación de esta celebración, el nuevo contexto del rito y, por ende, de su correlato agrícola-climático, y las emergentes dinámicas de resignificación y relacionalidad, otorgan renovados sentidos y efectos al complejo ritual.

Los deudos ahorran dinero durante el año para llevar a cabo esta conmemoración y celebrar con los difuntos, y un mes antes, la gente se moviliza para preparar lo necesario.

Dos semanas antes comencé a hacer las compras. Son muchas cosas que hay que alistar. Además los precios suben en Liniers. ${ }^{19}$ Compré todo lo necesario para hacer las t'antawawas,

19 Mercado más importante de la colectividad boliviana y centroandina, en general, de la ciudad de Buenos Aires.

\section{pa' hacer la chicha, hoja de coca. ¿Qué más? Otras cosas para decorar la mesa también (En- trevista a Elizabeth Oviedo. Buenos Aires, 7.07.2010. Notas del diario de campo). ${ }^{20}$}

Los procesos de comunalización entre los aymara, kolla y quechua llegados a Buenos Aires responden, en palabras de Richard Bauman y Charles Briggs (1990), a formas particulares de presuposición y creación de las tradiciones heredadas, con el propósito de dar sentido a las experiencias migratorias, los afectos y los nuevos lugares de apego.

Para describir este juego de presuposición-creación, retomo las tres principales ideas que tracé para este ritual en los Andes centrales.

\section{I) El hecho de morir no rompe los vínculos comuni-} tarios, los muertos siguen perteneciendo. En Buenos Aires, al igual que en los Andes centrales, al muerto se lo sigue honrando después de su muerte, a quien además de recordarlo, se lo invita a comer y beber todos los años.

II) Esta época, además del encuentro con los muertos, marca el inicio de la época femenina-húmeda. Más allá de la práctica de instrumentos de temporada de lluvia, no encontré ningún testimonio que hiciera referencia a aquellos sentidos. Esta ausencia es posible que responda a la falta de campesinos en el festejo porteño, ${ }^{21}$ razón a la cual podría sumársele el hecho de que el principio de noviembre no marca el inicio de la temporada de lluvias en Buenos Aires; ciudad donde llueve durante todo el año.

III) Quien muere es considerado en un estado liminal durante tres años. La división entre el primer año ("alma nueva") y los dos consecutivos, y el cierre de esta etapa, es una dinámica presente en Buenos Aires. La gran mayoría de las personas con las que conversé celebran tanto el 1 como el 2 de noviembre, principalmente, a sus difuntos con menos de tres años de fallecidos. Asimismo, como ocurre en

20 Elizabeth Oviedo, quechua y boliviana, es la protagonista del documental Tantawawas. Memoria del Indoamericano (García Recoaro, Mamani y Mardones, 2012).

$21 \mathrm{Al}$ menos para el caso de la ciudad de Buenos Aires y el cementerio de Flores. 
los Andes centrales, es posible encontrar familias que conmemoran con una menor parafernalia a sus muertos con posterioridad a este tiempo liminal.

La muerte evoca una etapa de este movimiento escalonado, constituyéndose el territorio -comprendido como espacio de reproducción social- en marco de referencia y generación de arraigo, apego y sentimiento de pertenencia socioterritorial de estos migrantes (Giménez, 2001).

Por lo general, primero migraron algunos integrantes de las familias, quienes luego de establecerse, conseguir trabajo y vivienda llevaron a otros de sus parientes o cercanos. A veces a sus hijos, primos; otras a sus padres/madres, tíos/as. Finalmente, en estas tierras lejanas fueron falleciendo. Algunos de los residentes en la ciudad de Buenos Aires pidieron ser enterrados en sus comunidades, pueblos o urbes de origen. Aunque la mayoría, por razones económicas, así como, en gran medida, por el deseo relacional de ser enterrado con "mi gente", hoy descansan preferentemente en el cementerio de Flores. Como lo evidencian los siguientes testimonios, ambas posiciones parecieran convivir:

A mi viejo lo fuimos a dejar a Oruro, ese fue su deseo. Él quería mucho su pueblo y por eso su deseo era descansar allá. Aunque yo vine de bien chiquita, también quiero que cuando me muera me manden para allá (Entrevista a Carla Cabrera. Buenos Aires, 2.11.2010. Notas del diario de campo). ${ }^{22}$

Le preguntamos si quería que lo mandáramos para Omasuyos [Depto. de La Paz]. Ya le veníamos preguntando cuando estaba bien malito. Pero dijo que no, que aqui vivia, aqui quería morirse. Dijo que quería quedarse con nosotros (Entrevista a Joselino Choque. Buenos Aires, 2.11.2009. Notas del diario de campo). ${ }^{23}$

22 Migrante boliviana y deuda ese ańo en el cementerio. Entrevista realizada para el documental Tantawawas. Memoria del Indoamericano (García Recoaro, Mamani, Mardones, 2012).

23 Migrante boliviano y deudo ese ańo en el cementerio. Entrevista realizada para el documental Tantawawas.
Tal como en los Andes centrales, en Buenos Aires el t'antawawa sigue siendo el protagonista más importante, el cual, como ya señalé, representa la personificación del "alma” (el ajayu). Tal vez por desconocimiento del idioma aymara o quechua y/o quizás debido a una simplificación para hacerse entender, hablan de otras figuras de pan también como t'antawawas. T'antawawas de caballo, t'antawawas de escalera, suelen decir. Al igual que en Bolivia, se decoran las figuras humanas de pan con máscaras de yeso.

He observado la presencia de apxätas, aunque en la inmensa mayoría de los casos, lo que priman son las mesas (Figura 2).

En Flores, al igual que el día anterior en los hogares, las mesas suelen estar acompañadas por velas (para llamar a las "almas"), guirnaldas, cigarrillos y generalmente epitafios (para poner el nombre del difunto). Suele haber hoja de coca, la cual pese a ser controlada en Argentina y Buenos Aires goza de circulación y mercado constante. La cerveza, chicha, vino y otros, a pesar de que se encuentran presentes en las mesas, al ser prohibidos por las autoridades del cementerio, su uso en este espacio está condicionado por los controles. En los últimos años, es evidente el incremento en la voluntad de los funcionarios por evitar su ingreso (Canelo y Vargas, 2001; Canelo, 2013).

Asimismo, es posible escuchar música de tarkeadas y pinkillos. Por su parte, aunque no es propio de época húmeda, al igual que como Machicao Arauco (2009) evidencia para el caso de Ovejuyo en la ciudad de La Paz, minoritariamente se interpreta el siku (Figuras 3 y 4). También abundan los aerófonos de bronce, especialmente trompetas, acompañados por bombos de banda.

La denominación resiris o rezadores refiere a otra de las tradiciones que se actualizan en el cementerio, aunque a diferencia de sus usos en algunas partes de la región centroandina, aquí no son solo los menores los que cumplen ese rol, sino que es posible ver a familias enteras rezando por los muertos y

Memoria del Indoamericano (García Recoaro, Mamani, Mardones, 2012). 


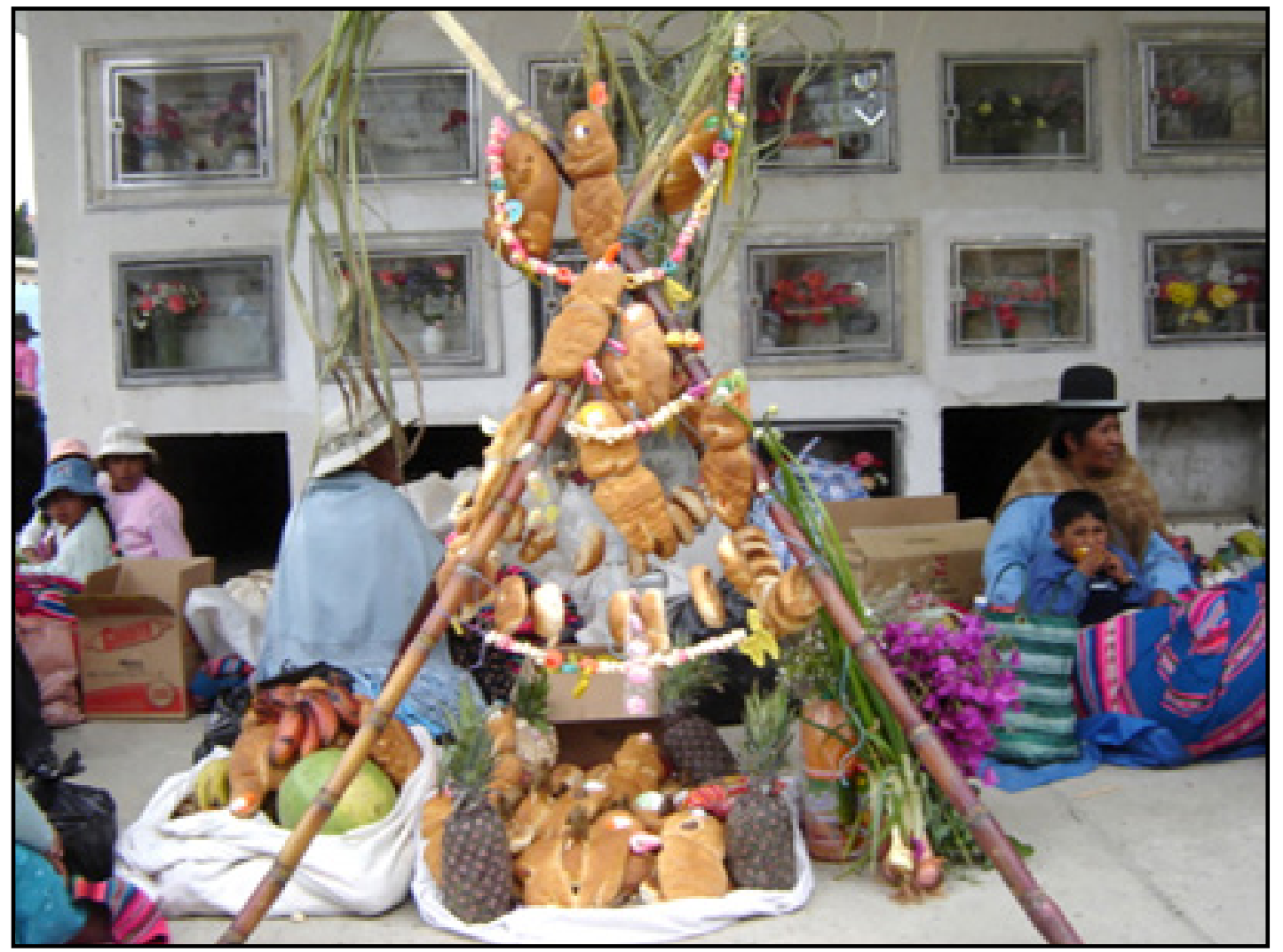

Figura 2. Apxäta. Registro: Periódico Renacer. 2 de noviembre de 2008. Buenos Aires, Argentina.

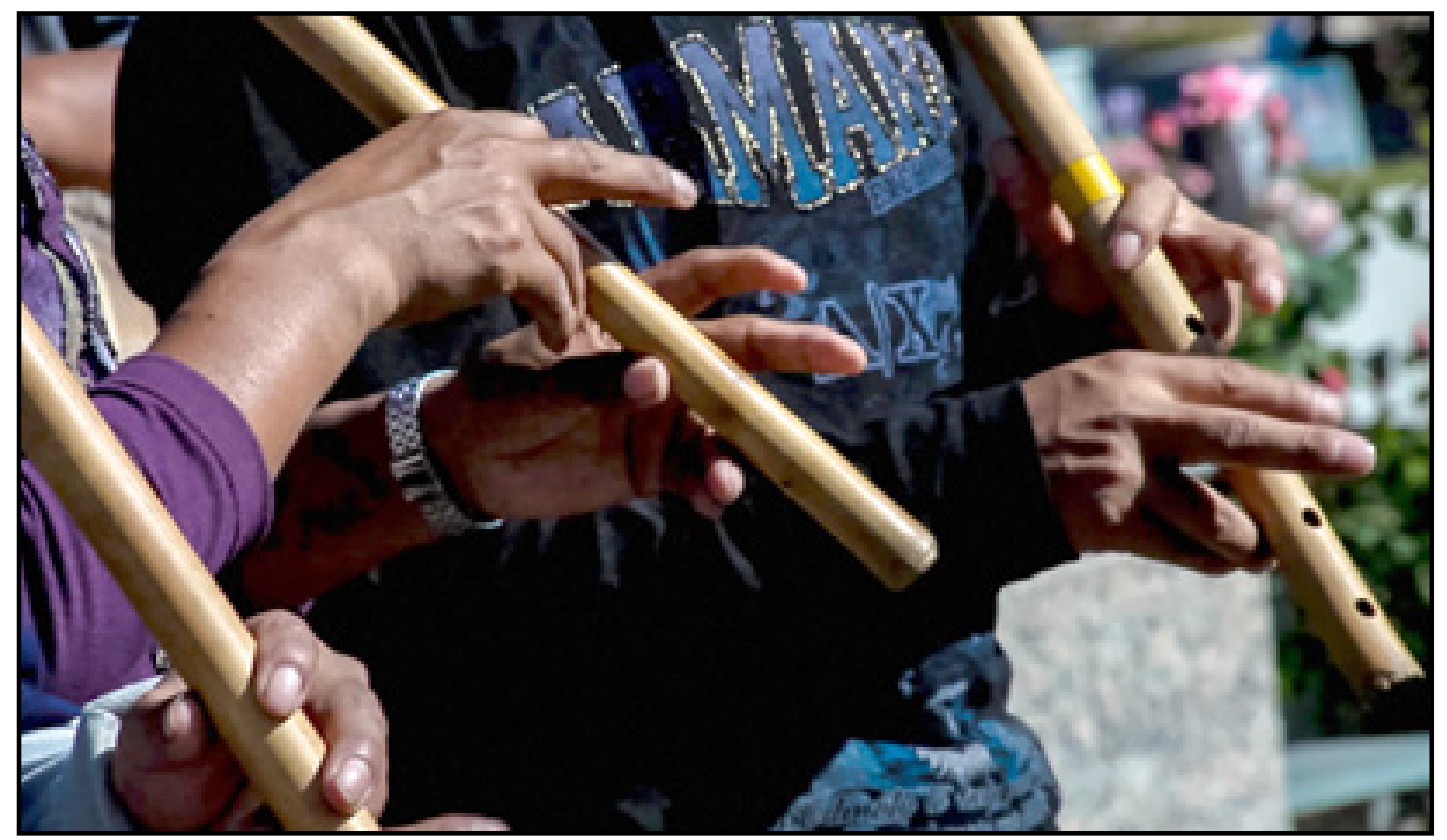

Figura 3. Comunidad Markasata interpretando un tipo de pinkillo.

Registro propio: 2 de noviembre de 2011. Buenos Aires, Argentina. 


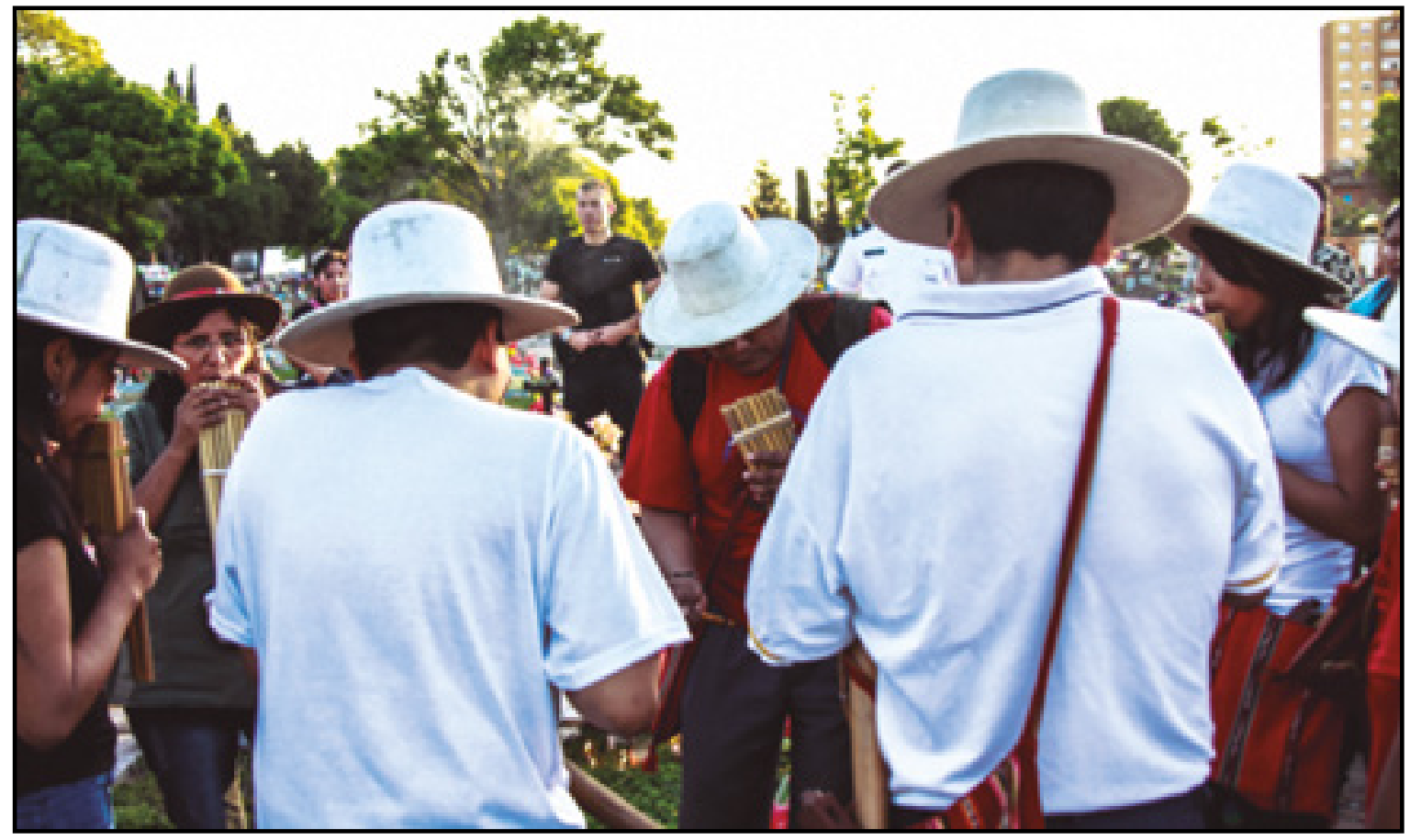

Figura 4. Centro Cultural Autóctono Wayna Marka tocando siku. Registro propio: 2 de noviembre de 2011. Buenos Aires, Argentina.

recibiendo alimentos y bebidas a cambio. En Buenos Aires, resiris, sean niños o adultos, a diferencia de los músicos, no reciben dinero a cambio de sus oraciones cantadas, sino que comida, generalmente figuras de pan además de pasancalla (maíz inflado) y confites.

Tal como en los Andes centrales, en Flores, se reparte todo al finalizar. Quienes son deudos tienen muy claro que es mala fortuna volver con alimentos o bebidas al hogar, lo cual es muy difícil de lograr, ya que a las seis de la tarde cierra el cementerio, obligándolos a retirarse, incluso bastante tiempo antes de esta hora (Figura 5).

En Buenos Aires, al igual que en el altiplano andino, está presente la creencia del retorno anual de las "almas". El siguiente testimonio es ilustrativo:

Este día se recuerda con mucho más fuerza. Este día el "alma" viene a participar con nosotros, y por eso le hacemos una fiesta [...]. Ese día nosotros recibimos una visita de ellos, por eso esperamos el medio día este día, entonces hacemos un pequeño altar con estas figuras de pan y hacemos algunas comidas que les gustan a ellos [...] es un día de motivación, es convivir ese día con esa persona que tenías cerca. Capaz que mañana es un día normal para las personas que están aqui en el cementerio, y se espera un día más para recordarlo [...] pero una vez al año sí o si nos reencontramos con esas personas. $Y$ creo que se siente, al menos las personas que hacemos esto lo sentimos (Entrevista a Gervasio Cortés. Buenos Aires, 2.11.2009. Notas del diario de campo). ${ }^{24}$

Por su parte, uno de los elementos que no se encuentran en Flores son el homenaje a las ñatitas (cráneos) descrito por Fernández (2011) para la ciudad de La Paz y El Alto. Esta ausencia me llamó la atención, considerando que muchos migrantes provienen de estas dos ciudades.

24 Migrante boliviano y deudo ese año en el cementerio. Entrevista realizada para el documental Tantawawas. Memoria del Indoamericano (García Recoaro, Mamani y Mardones, 2012). No fue considerada en la versión final. 


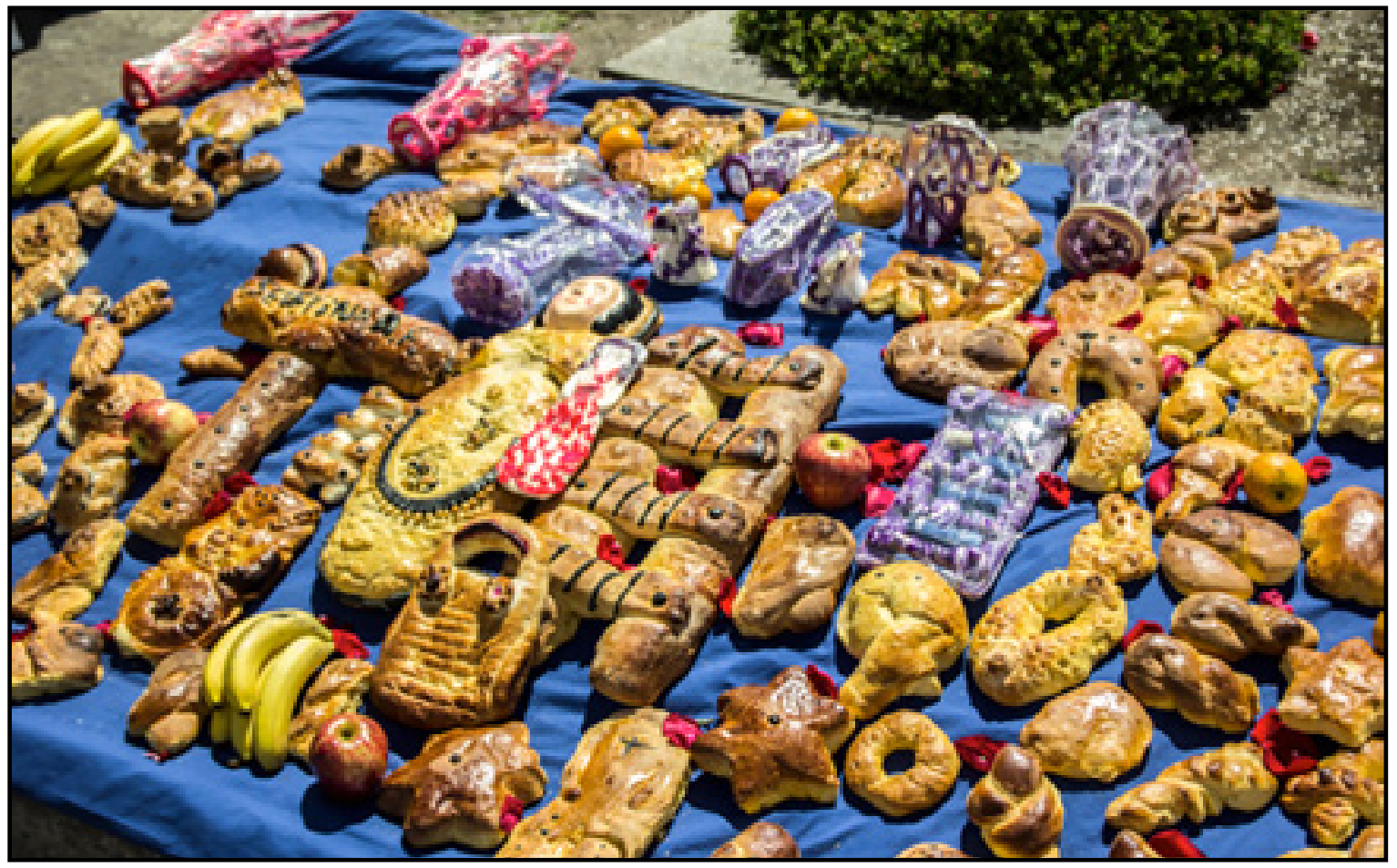

Figura 5. T'antawawas. Registro propio: 2 de noviembre de 2016. Buenos Aires, Argentina.

Al igual que en las ciudades de La Paz y El Alto, la fiesta no comienza varias semanas antes (Fernández, 2011) ni dura hasta el 3 de noviembre (Berg, 1989; Fernández, 1998), sino que su término ocurre, sin excepción debido a los tiempos acotados del cementerio, en la tarde del día 2. "Aqui por ahi es por los permisos de la municipalidad. Hoy a la noche ya no [2 de noviembre]. Aqui terminamos en el cementerio, venimos al último reencuentro" (Entrevista a Joselino Choque. Buenos Aires, 2.11.2009. Notas del diario de campo).

Vargas me cuenta que hasta hace algunos años se acostumbraba ir, después del cementerio, al parque Indoamericano a seguir el festejo, pero que luego de la toma, represión, expulsión y cierre parcial de este parque en 2010, esta costumbre mermó notablemente.

La lectura de distintas descripciones etnográficas me permitió identificar algunas generalidades y principios comunes. En este sentido, la celebración en el cementerio de Flores representa una nueva versión del evento, en la que se actualizan muchas de las prácticas y sentidos compartidos en una vasta región, al tiempo que otros se amoldan a los condicionamientos urbanos de Buenos Aires y otros más se resignifican desde la experiencia migratoria. Si entendemos el ritual simultáneamente como marco de interpretación heredado y como producto histórico contingente, este se vuelve dinámico y creativo en sus modos de resignificación. Con la llegada de distintos migrantes de comunidades rurales y, particularmente, debido a la consolidación de la festividad y la vitalización centroandina en Buenos Aires, fueron emergiendo elementos y usos que hasta ese momento no habían aparecido.

\section{Los tiempos rituales en Buenos Aires}

En la ciudad de Buenos Aires, la tradición ritual del culto y festejo a los muertos opera a través de la transmisión oral y como ejercicio de identificación. De esta manera, la significación de roles, elementos y tiempos se transmite conscientemente de unos a otros durante los dos días que dura la fiesta. En algunos casos esto se hace para que los más jóvenes aprendan los conocimientos de su comunidad; en 


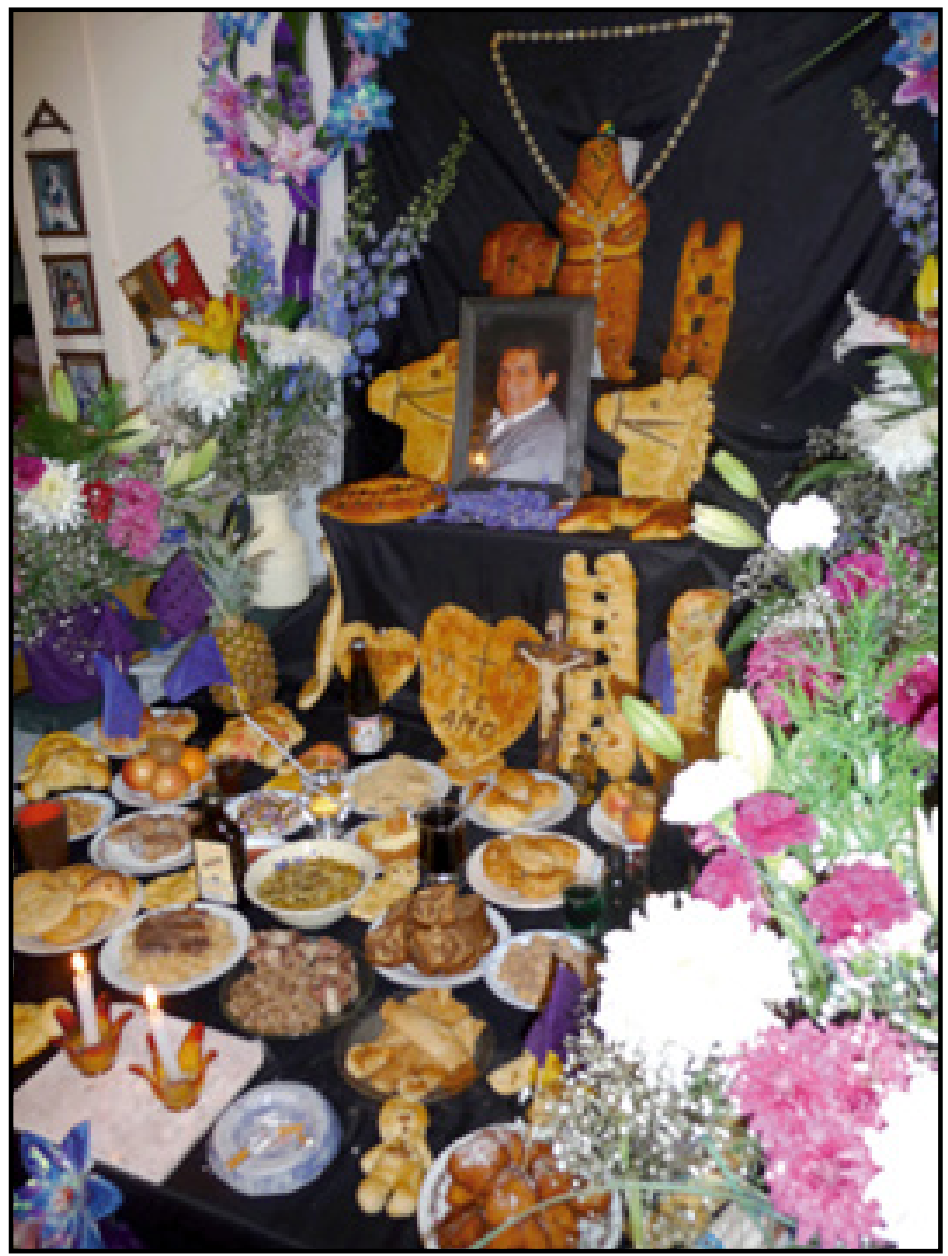

Figura 6. Mesa de Manuel Remonte. Registro propio: 1 de noviembre de 2009. Buenos Aires, Argentina.

otros, para compartir diferencias y similitudes entre vecinos. De acuerdo con sus propias reflexiones, el aprendizaje es considerado como un mecanismo de conservación en el nuevo espacio migratorio constituido por diversas trayectorias y movimientos (De Certeau, 1996), es decir una forma de recontextualizar las subjetividades afectivas que los constituyen. Sin embargo, en cada recontextualización se reorganizan también los sentidos de un endogrupo (a veces bolivianos, otras centroandinos, incluyendo peruanos y nordesteños y sus descendientes) y de un exogrupo (argentinos, porteños) (Figura 6).

Tal como en los Andes centrales, el 1 de noviembre las actividades se centran en las viviendas de los familiares del difunto. Los preparativos comienzan en las primeras horas de la mañana, cuando los deudos y colaboradores (familiares, vecinos y amigos) elaboran en sus casas una mesa (también conocida como altar o altarcito). Esta suele tener tres pisos o plataformas, acorde con la cosmovisión centroandina de los tres niveles cosmogónicos (hanan o alak pacha, aka pacha y urin o manka pacha) y coincidentes con la homologación cristiana (cielo, tierra e infierno). Al mediodía, debe estar lista. Por lo general, en su parte más alta van los caballos ${ }^{25}$ y las escaleras, ${ }^{26}$ para que el difunto se mueva hacia los otros niveles.

25 A diferencia de los Andes centrales, en la ciudad de Buenos Aires no es muy común ver panes de llamas.

26 En 2009 tuve el privilegio de quedarme con un caballo y el 2011 con una escalera, aunque para eso fue necesario que rezara. Como no sé muy bien la oración del padrenuestro, tuve que escuchar a muchos resiris pronunciarla para luego, con bastante vergüenza, hacerlo yo. 


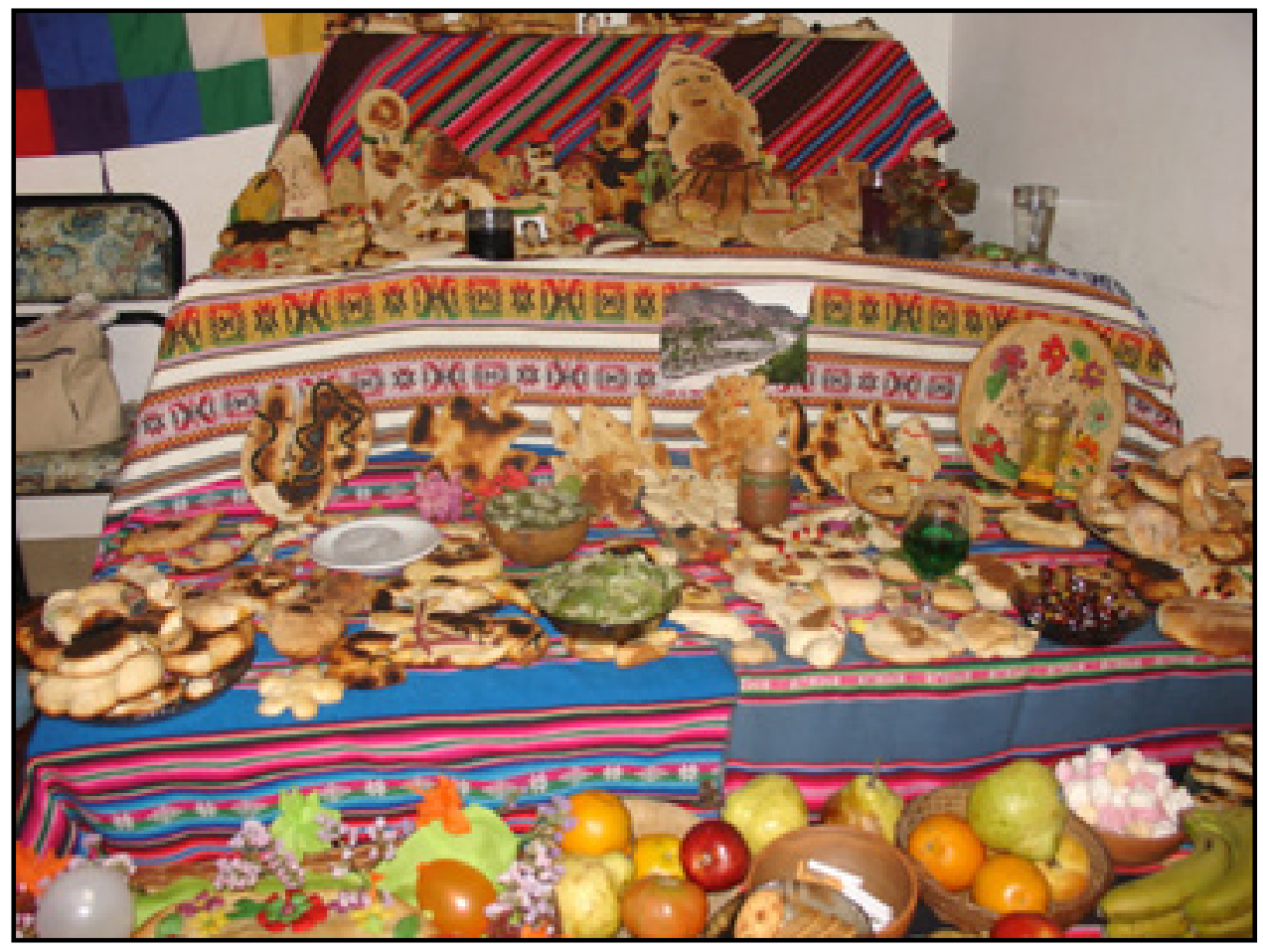

Figura 7. Mesa de Hugo Chañi. Registro: Periódico Renacer. 1 de noviembre de 2008. Buenos Aires, Argentina.

En ese mismo nivel se coloca una foto del difunto y las simbologías estelares: estrellas, soles, lunas. En el piso intermedio -que simboliza el presente, el mundo de los vivos (akapacha) - se disponen los elementos que caracterizan al difunto. Como por ejemplo un cenicero con un cigarrillo, si fuma, o el licor que le gusta. Aquí, y también en el piso inferior, podemos observar los gustos y usos culturales que fue adquiriendo la persona en el nuevo país de acogida, como el mate o el escudo de su equipo de fútbol argentino. Finalmente, en el nivel inferior, hasta cierto punto el más importante, ya que representa el lugar donde viven los muertos (urin o manka pacha) (Berg, 1989), se colocan los t'antawawas y los platos de comida. De esta forma, los platos típicos de los Andes centrales, como la sopa de maní, el picante de pollo o la empanada salteña, conviven con algunos propios de la gastronomía porteńa, como pastas y pizzas. En este nivel también suelen colocarse frutas, junto con galletas y a veces globos (Figura 7).

En algunas oportunidades, probablemente para evitar complejidades en el armado, solo se dispone de dos pisos. Es usual ubicar una mesa pequeña sobre una más grande, ambas cubiertas por una tela negra o morada, generando de esta manera dos pisos o niveles.

Otra característica que en contexto migratorio adquiere gran relevancia, es la personificación de las mesas, las cuales son adornadas con elementos propios. A veces, suman una whipala, ${ }^{27}$ postales de sus pueblos o ciudades de origen, escudos de su club de fútbol preferido en Bolivia, dibujos de sus hijos o sobrinos, entre otros. De esta forma, cuando se visitan las mesas de ofrenda de distintas familias que esperan el "alma nueva", se puede reconocer de qué área es cada familia. La preparación de las mesas constituye, así, una práctica de objetivación de las historias personales, en la que se conjuga la memoria de sus orígenes con experiencias migratorias propias de la familia y su difunto.

27 Bandera cuadrangular de siete colores utilizada por grupos y personas de los Andes centrales. Actualmente, también es asimilada por amerindios de otros territorios, llegando a considerarse como "bandera de los Pueblos Originarios". 


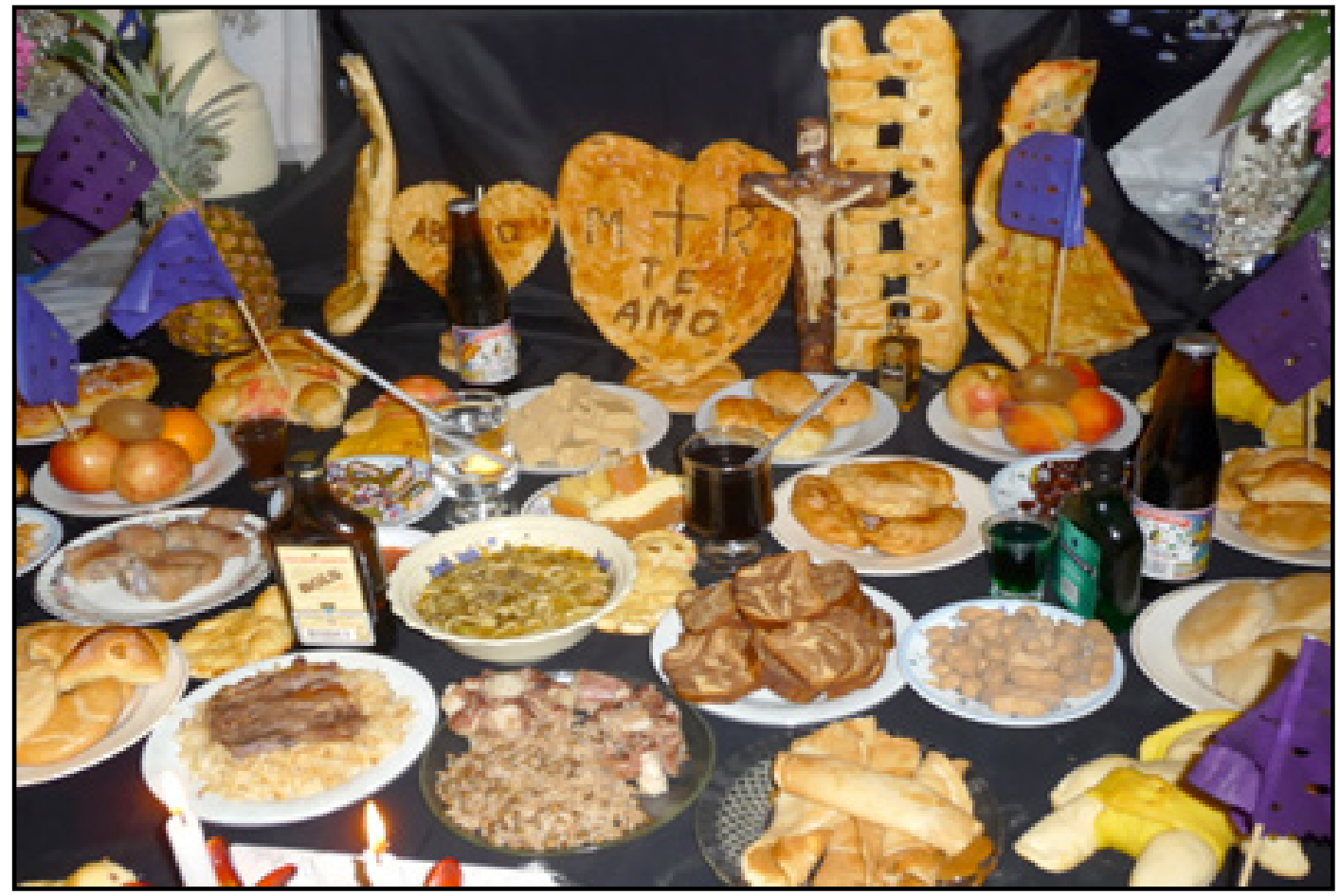

Figura 8. Mesa de Manuel Remonte con distintos elementos. Registro: Periódico Renacer. 1 de noviembre de 2009. Buenos Aires, Argentina.

Mi marido era orgulloso de su origen orureño, por eso le pusimos el escudo del San José [equipo de fútbol de la ciudad de Oruro] (Entrevista a Lidia Remonte. Buenos Aires, 6.08.2010. Notas del diario de campo).

Pusimos las fotos de varios familiares que eran cercanos, algunos están en Cochabamba, otros están aqui con nosotros. Para él todos eran muy queridos (Entrevista a Gervasio Cortés, 2009. Notas del diario de campo).

Esta objetivación de las trayectorias familiares y personales resulta crucial en Buenos Aires, donde los encuentros en lugares comunes de apego se dan entre personas que no se conocen entre sí. Estrategia innecesaria en las comunidades en las que todos saben quién es el otro, resultando en vano identificarse. De esta forma, las mesas o altares, como expresiones de memoria, devinieron soporte para poner en común la experiencia migratoria dentro de los marcos comunicativos e interpretativos de una tradición compartida.
La noche del 1 al 2 de noviembre, las familias con mesas de difuntos son visitadas, se bebe cerveza, vino u otro licor, se habla de ellos y se reza. Es un momento muy íntimo y sensible cuando puede sentirse cómo el difunto nos acompańa. A cierta hora, en algunos casos, la habitación en la que se encuentra la mesa es cerrada para que las "almas" puedan disfrutar de su festejo a solas; es el momento en el que descienden para probar las delicias que les han preparado, las que son degustadas a través del olor que despiden las preparaciones (Figura 8).

Como producto de la articulación de pertenencias cristianas y centroandinas, en Buenos Aires, se evidencia una división no taxativa de creencias entre los migrantes que ejecutan este ritual. Mientras unos dan privilegio a las prácticas y elementos cristianos, rezos, oraciones, cruces, rosarios, otros adscriben, mayoritariamente, a aquellos propios de los Andes centrales, preparando un apthapi ${ }^{28}$ armando

28 Apthapi refiere a la costumbre de compartir alimentos entre los miembros de una colectividad, amigos o familiares, teniendo como objetivo socializar, unir o 
una wajta, ${ }^{29}$ ejerciendo $a y n i^{30}$ o venerando a la $\mathrm{Pa}$ chamama.

En general, como es posible apreciar en las fotos, entre la multitud de mesas se observan dos prototipos. Uno referido a aquellas confeccionadas con un fondo de tela negro, las cuales por lo general tienden a estar acompañadas con elementos litúrgicos cristianos. El otro, a aquella mesa armada sobre uno o varios aguayos, ${ }^{31}$ en la que suele haber hoja de coca (para que el espíritu se sienta satisfecho), así como otros motivos o símbolos de las tradiciones centroandinas, como la Chakana ${ }^{32}$ y la Whipala.

A continuación, relataré tres ejemplos que conocí del festejo del 1 de noviembre, los que denotan las distinciones que esgrimo. En el primer caso, se encuentran los Remonte, familia de clase media cuyos miembros se autodefinen como mestizos de la ciudad de Oruro. El difunto, don Manuel Remonte, es un profesional que migró hace más de 50 años, dejando al morir varios hijos, algunos nacidos en Bolivia, otros en Argentina, así como un gran número de nietos argentinos. Su mujer Lidia Remonte, me contó:

\section{Nosotros no teniamos la tradición de festejar este día, lo veíamos como cosa de indios [...] solo íbamos al cementerio, pero no armábamos la mesa, ni comidas, ni nada de eso. Fueron unas vecinas que me enseñaron, ahi le fuimos tomando importancia [...] como Manuel mu- rió aqui, que fue su segundo hogar, vivió tan-}

reconciliarse con la comunidad o familia.

29 Traducido como ofrenda.

30 Reciprocidad de intercambio de ayuda a nivel comunitario. Se trata de un favor entregado o una prestación de servicio que luego será devuelto de la misma forma o su equivalente.

31 Se trata de una prenda rectangular de colores fuertes y contrastantes con diversos diseños, preferentemente franjas. Es usada como adorno, mantel, bolso para llevar a un bebé o diversas cosas, o como abrigo. Es de origen altiplánico, usado principalmente por mujeres. Debido a la migración y a lo bello de sus diseños, se ha hecho habitual en diversos lugares del continente.

32 Ícono sagrado de los Andes centrales, representado por las cuatro estrellas que forman la constelación de la Cruz del Sur. Significa cuatro escaleras o cuatro puentes en aymara y quechua, respectivamente, y ha sido traducida como cruz andina (Milla, 1983). tos años, fue bonito poder hacerlo (Entrevista a Lidia Remonte, 2010).

Como grafica este testimonio, en Bolivia no todo el mundo festeja este rito, pues es considerado por algunos como "cosa de indios". Por otro lado, evidencia que la migración posee un carácter performativo particular sobre la resignificación de tradiciones, las cuales adquieren un valor en destino que no tenían en el origen. Así, "familias mestizas", como la Remonte, comienzan a apropiarse de ciertas tradiciones, considerando que también son propias en tanto "bolivianas", o que, si no lo son, pueden ahora serlo en su condición de migrantes.

Los Choque, en cambio, resignifican la tradición aymara-quechua o kolla del rito, al igual que lo hacen con otros hitos del calendario anual. Se trata de una familia que junto a otros indígenas milita desde el activismo social, cultural y política por la reivindicación de los "pueblos originarios". De esta forma, rechaza los usos cristianos en los ritos amerindios, así como practica un discurso de recuperación de las tradiciones negadas y vapuleadas por el colonialismo europeo y posteriormente republicano (Figura 9).

Nosotros no creemos en la Iglesia cristiana. La Iglesia lo que hizo fue querer hacernos desaparecer, que lo nuestro no valiera. Nosotros nos sentimos pueblos originarios, y por eso ponemos nuestros simbolos, la whipala, la chakana, la quilla (luna), el inti (sol) (Entrevista a Cafdey Choque. Buenos Aires, 11.10.2009. Notas del diario de campo).

Finalmente, algunas familias utilizan sincréticamente elementos rituales-culturales centroandinos con otros cristianos. Este es el caso de Elizabeth Ovidio, viuda de Emilio Canaviri Álvarez, asesinado en la toma del parque Indoamericano de la ciudad de Buenos Aires en diciembre de $2010 .{ }^{33}$ Nacida en Cochabamba de familia quechua, vivió durante mucho

33 Entre 2010 y 2011, junto a dos colegas, realicé el documental Tantawawas. Memoria del Indoamericano (García Recoaro, Mamani, Mardones, 2012), el cual da a conocer de qué modo Elizabeth Ovidio lleva a cabo la celebración del Día de los Difuntos encontrándose con su marido, a su vez que relata su asesinato en la toma del parque Indoamericano. 


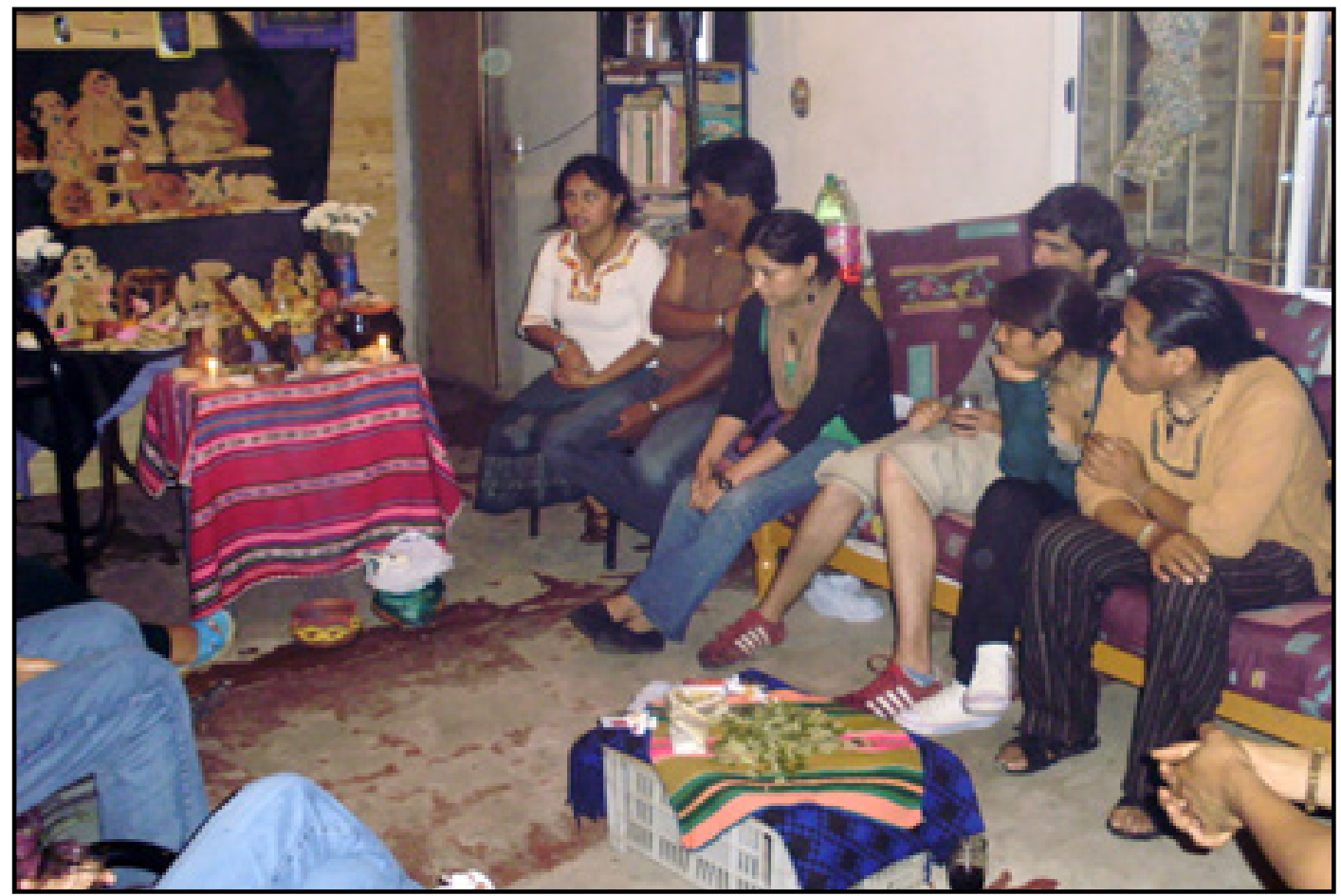

Figura 9. Casa de la familia Choque.

Registro: fotografía compartida en facebook. 1 de noviembre de 2010. Buenos Aires, Argentina.

tiempo en un pueblo aymara del Departamento de Oruro, lugar del cual era originario su marido. Ella manifestaba:

Nunca he participado [...] Por eso cuando mi marido murión ${ }^{34}$ he hecho con la iglesia nada más [...]. Lo único que ese día pensé es llenarle de flores, llenarle de pan, llenarle de fruta, de todo [...] no sabía cómo se acomodaban ni a qué lado iban. Por suerte la vecina sabia y ella me dio una mano. Se ofreció a decirme: "Mirá, no lo hagas así. Hazlo de esta manera". Lo hice como yo pude, de costumbres no sé... Mi familia no me dio mucho porque cuando era chiquita mis abuelos murieron. No sabemos hacer, yo no sé hacer costumbres asi muybien. Hice lo que pude. No sé si me salió bien o

34 Emilio Canaviri Álvarez fue asesinado en diciembre de 2010, por lo que tal como la creencia manifiesta, su "alma" volvió el 2 de noviembre siguiente, ya que "si la persona muere en noviembre, diciembre o enero, el primer aniversario es celebrado en el siguiente Todos Santos" (Berg, 1989, p. 14). me salió mal (Entrevista a Elizabeth Oviedo. Buenos Aires, 7.07.2010. Notas del diario de campo).

Ella expresa la importancia afectiva que le otorga al ritual, pero reconoce que no sabía cómo llevarlo a cabo, mostrándose agradecida de la vecina que le ayudó. "Yo al principio habia puesto un aguayo, pero ella [la vecina] me lo cambió por esta tela negra [...] yo prefería el aguayo pero bue" (Elizabeth Oviedo, 2010) (Figura 10).

En los tres casos descritos, es posible observar la importancia de la vecindad y de su relación en la comunalización que se pone en marcha en los barrios conformados mayormente por migrantes. Tanto la familia Remonte como la familia Oviedo viven en barrios habitados principalmente por la comunidad boliviana. En el primer caso, en uno de clase media en Parque Chacabuco; en el segundo, en un barrio popular cercano a la feria Bonorino en Flores. En estos ejemplos vemos cómo el armado de la mesa $y$, posteriormente, su despliegue en el cementerio 


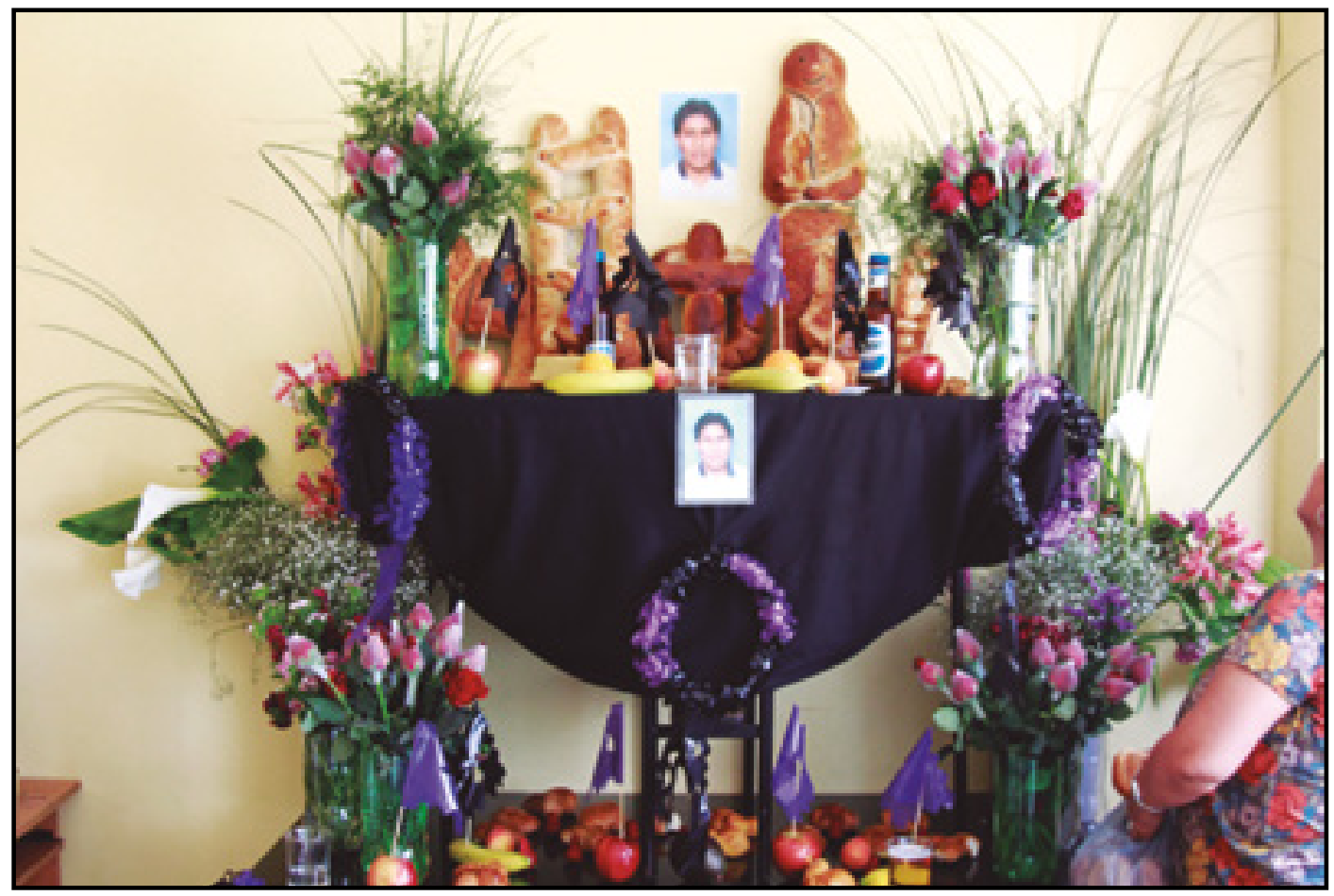

Figura 10. Mesa de Emilio Canaviri Álvarez.

Registro propio: 1 de noviembre de 2011. Buenos Aires, Argentina.

operan como sitios de memoria familiar y comunal, actualizando tanto experiencias del pasado más lejano (Bolivia) como del presente (Buenos Aires). Los elementos rituales con los que se evocan ambos espacios, junto con las preferencias religiosas e ideológicas que también se objetivan en el armado de las mesas, van denotando el lugar afectivo y cultural donde vivió y vive el difunto, al tiempo que refuerza los sentidos de pertenencia de sus familias y comunidades.

Asimismo, el espacio de acogida genera nuevas pautas y el involucramiento de actores argentinos y/o miembros de otras colectividades que participan en dicha dinámica. Esta condición enriquece y estimula el patrimonio ancestral de estas tradiciones a la vez que impulsa un proceso intercultural en la generación de lazos de intercambio dentro de la pluriétnica sociedad porteña.

Los trabajos de Machicao Arauco (2009) en la zona periurbana de Ovejuyo, al sur de la ciudad de La Paz, y de Fernández (2011) sobre la veneración a las ñatitas (cráneos) en el Cementerio General de la ciudad de La Paz, permiten comprender que muchas de las transformaciones en las prácticas rurales que se observan en Buenos Aires han sufrido cambios muy similares en el contexto urbano de los Andes centrales. Como antes mencioné, Machicao Arauco evidencia cómo, a diferencia de la ruralidad y al igual que en la capital argentina, en Ovejuyo se tocan instrumentos musicales que no son propios de esta época del año y se colocan fotografías de los difuntos. Por su parte, Fernández explica el culto urbano a las ñatitas, en el que el domingo siguiente al Día de los Muertos, habitantes de las ciudades de El Alto y La Paz llevan estas representaciones mortuorias al cementerio para ser veneradas.

La ciudad de Buenos Aires dispone de tres cementerios estatales. El de la Recoleta, el de Chacarita y el de Flores. Tal como da a conocer Canelo (2006), citando a la Dirección General de Cementerios, el primero es concebido como el camposanto más importante del país, debido a su majestuosa arquitectura y las personalidades allí enterradas (Evita Perón, Domingo 
Faustino Sarmiento, Juan Manuel de Rosas, entre otros). El cementerio de la Chacarita, por su parte, aparece descripto como uno de los más grandes a escala mundial, mientras que el de Flores es diferenciado como un cementerio "de pueblo". Canelo también contrasta los barrios de emplazamiento de estos cementerios. Mientras que la Recoleta corresponde a uno de los sectores más exclusivos y acaudalados de la ciudad, Chacarita a uno de ingresos medios y medios altos; Flores -junto a los demás barrios del suroeste de la ciudad- concentra a clases medias y bajas, entre las cuales la población migrante de la región andina central alcanza una alta representación.

El día 2 de noviembre, las familias desarman la mesa armada el día anterior en sus casas para trasladarla con todos sus elementos al cementerio. Generalmente, son acompañados de familiares y amigos cercanos que pasaron la víspera del 1 con ellos. Para este segundo día realizan una invitación ampliada a la familia extensiva, amigos, conocidos y vecinos, particularmente los tres primeros ańos.

Hasta bien pasado el mediodía se observa poca gente, preponderantemente mujeres. Según la tradición, el "alma" llega al mediodía del 2 de noviembre, pero en la Argentina, a diferencia de la mayoría de los países latinoamericanos no es feriado, ${ }^{35}$ como antes seńalé, por lo que los deudos, en alto porcentaje trabajadores empleados, solo pueden llegar por la tarde, en la medida que se van desocupando o pidiendo permiso en sus respectivos empleos.

Desde antes del mediodía, se puede ver a las personas llegar solas o acompañadas llevando flores y aproximarse a tumbas y bóvedas (Figura 11).

Se ve a varias familias limpiando el lugar, quitando flores muertas y botellas vacías que ya estaban ahí (quizás desde el año anterior), y realizando un arreglo con flores coloridas y guirnaldas. ${ }^{36}$ Desde

35 Fue retirado, al igual que el feriado de carnaval, por la última dictadura el año 1978, aunque este último fue repuesto por el segundo gobierno de Cristina Fernández en 2011.

36 Según la tradición, deben ser de color blanco, rosado y celeste si son niños; amarillo y celeste para jóvenes, y negro y morado si se trata de personas adultas (Berg, 1989; Fernández, 1998). aproximadamente las dos de la tarde, el cementerio comienza a llenarse, muchas veces, en camionetas o combis, con panes, frutas, pasancalla, gaseosas, heladeritas, vasos, platos, sillas, mesas, paraguas para el sol y/o la lluvia, y, si es que logran sortear el control, con cerveza y chicha, entre otras bebidas.

Utilizando todo el espacio del cementerio, alrededor de las tumbas se reúnen familiares, amigos y vecinos en grupos cuyo número depende de la cantidad de familiares y popularidad del difunto.

La tarde transcurre con personas solas o familias completas que se acercan y rezan padrenuestros y avemarías, preguntando previamente el nombre del difunto y si se trata de un "alma nueva" o machaqani (primer ańo). Luego de la plegaria ofrecida reciben una bolsa con algunos t'antawawas y golosinas, además de un vaso de gaseosa, jugo o, cuando se puede, de cerveza o chicha. Algunos challan ${ }^{37}$ la tierra con el líquido ofrecido antes de beber. Cada tanto, y dependiendo del poder adquisitivo de los familiares del difunto, se contrata a músicos que circulan por el cementerio ofreciendo sus servicios por dinero. Aquí se encuentran tarkeadas, pinkilladas, sikureadas ${ }^{38}$ y grupos de bronces (principalmente trompetas).

Durante 2008, 2009 y 2010 participé como músico, tocando tarkas y sikus invitado por el Centro Cultural Autóctono Wayna Marka. En 2016 lo hice con la agrupación Lakitas del Oriente. En estas experiencias pude apreciar la relevancia de los músicos en esta festividad, quienes, contratados por los deudos, asumen una gran responsabilidad al ser permanentemente requeridos.

En 2008, la primera vez que acompañé a Wayna Marka, al final de la tarde cuando repartían lo recaudado a cada integrante, les agradecí por haberme invitado y rechacé el dinero. Ellos insistieron, argumentando que era deseo de las "almas".

Este y los ańos venideros en que participé junto a esta agrupación, viví desde adentro la relevancia del rol de músico durante esta fiesta. Los deudos se

37 Acto de rociar, asperjar o verter bebida alcohólica para saludar, bendecir o gratificar un objeto o un lugar.

38 Ambos aerófonos autóctonos de los Andes centrales. 


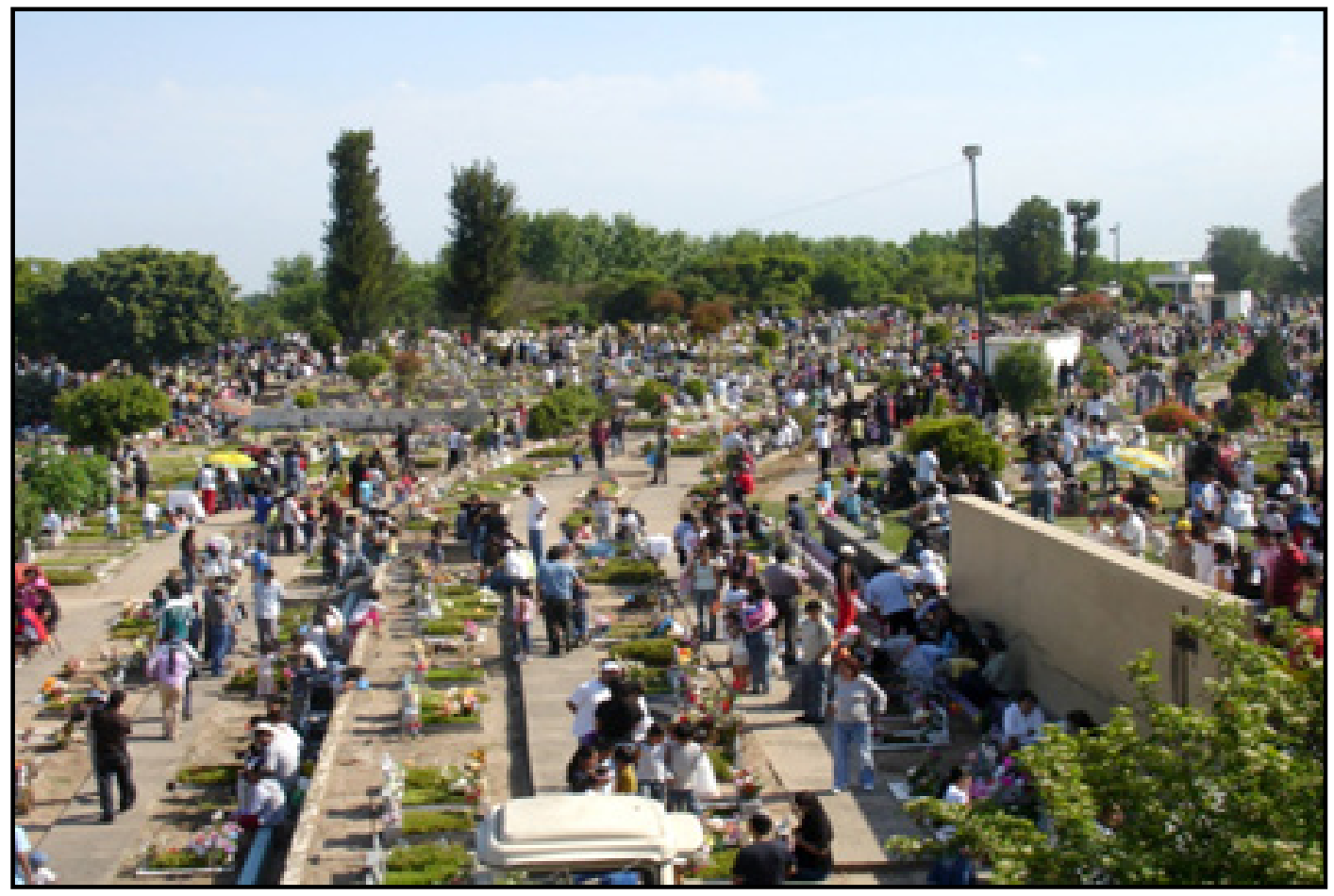

Figura 11. Vista general del Cementerio de Flores.

Registro: Periódico Renacer. 1 de noviembre de 2009. Buenos Aires, Argentina.

acercan y van solicitando el servicio musical para sus muertos. La dinámica consiste en acercarse a la tumba y tocar entre tres y cuatro temas. Muchas veces los deudos solicitan alguna canción particular que era de gusto del difunto. Luego de esto, los familiares pagan a los músicos un precio previamente establecido por el servicio. Son tantas las solicitudes, que hay que estar muy atento para mantener el orden de presentaciones.

En 2016, cuando decidí ir a tocar con mi propia agrupación, esta situación se había incrementado de forma notable. El gobierno de la ciudad de Buenos Aires decidió no permitir el ingreso de instrumentos musicales, lo que implicó que la mayoría de las agrupaciones se fueran a tocar al parque Roca, ubicado en el barrio de Lugano. Frente a esta prohibición, con Lakitas del Oriente decidimos tocar fuera del cementerio y ante un descuido de los celadores, mientras ingresaba gran cantidad de personas, ingresamos camuflando nuestro bombo de gran tamańo. Una vez dentro, debido a la escasez de músicos, fuimos sobredemandados (Figura 12).
Fue tal la cantidad de solicitudes, que uno de nosotros tuvo que anotarlas para evitar altercados entre los deudos.

El 2 de noviembre en el cementerio de Flores -como algunos autores identifican para la ruralidad de los Andes centrales (Berg, 1989; Fernández, 1998; Ferraro, 2004)-, es celebrado en clave comunitaria, justamente, porque su lógica ritual responde a esa dinámica. Al no ser un encuentro casual, sino uno en el que personas conocidas y desconocidas entre sí, y con trayectorias heterogéneas, se cruzan espontáneamente en un sitio común de apego, este objetiva un determinado tipo de conexión, el cual actualiza un sentimiento valorado y practicado que exterioriza los vínculos con sus ancestros.

Frente al deseo de establecer nuevos sentidos de pertenencia como migrantes (aymara, kolla, quechua, bolivianos, peruanos, nordesteños, y sus articulaciones), la masificación reciente del rito de los muertos en el cementerio de Flores representa un logro colectivo con fuerza aglutinadora: el despliegue público 


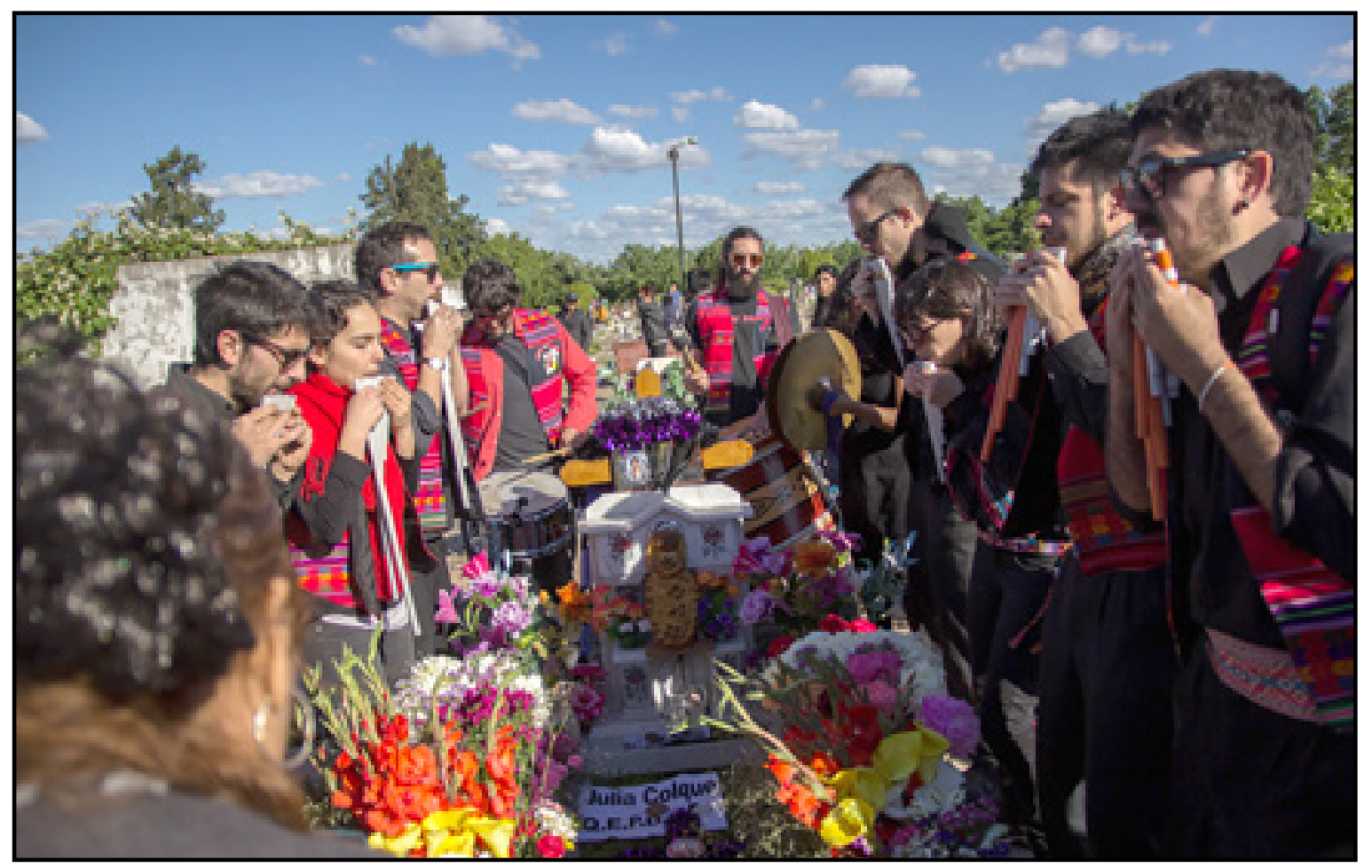

Figura 12. Lakitas del Oriente. Registro: Tamara Fernández. 2 de noviembre de 2016. Buenos Aires, Argentina.

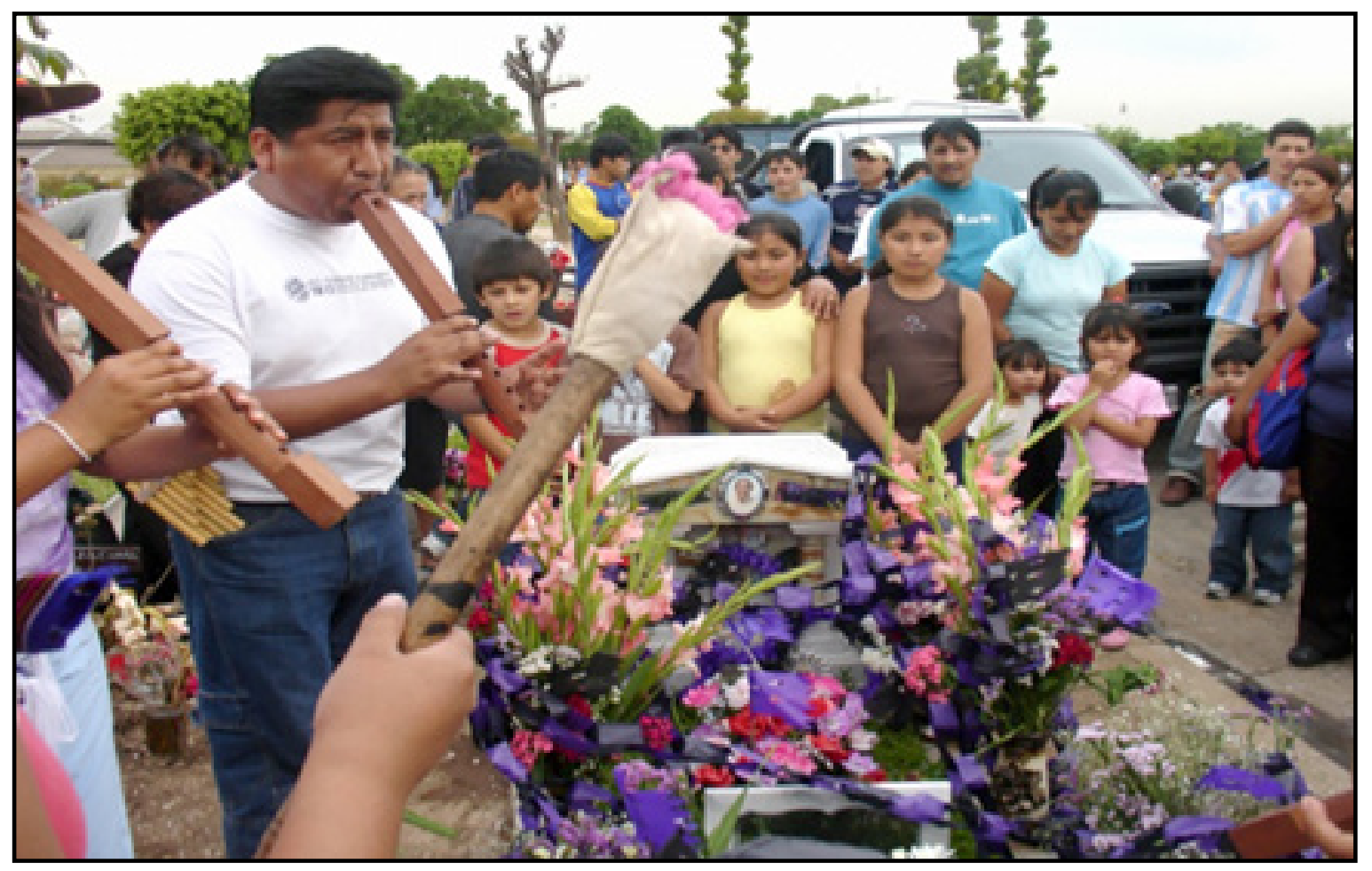

Figura 13. Tarkeada. Registro propio: 2 de noviembre de 2009. Buenos Aires, Argentina. 
de una apropiación espacial realizada de acuerdo con marcos significativos de interpretación.

Desde que esta fiesta se celebra masivamente en el cementerio de Flores, emergieron otros sentidos que, a través de distintas prácticas, fueron produciendo interpretaciones rituales inscriptas en experiencias urbanas y migratorias (Figura 13).

Estas recreaciones se aprecian especialmente en las mesas, el 1 de noviembre en el ámbito privado, con el armado y decoración, y el día 2 en el público. Estas son confeccionadas como una representación de experiencias migratorias y dinámicas de identificación que oscilan entre los lenguajes del cristianismo y de la cosmovisión centroandina, de los ciclos rurales y las marcaciones urbanas, así como de los lugares de origen y los sitios de habitación actual.

Se trata de una práctica que, aprendida por transmisión oral, se manifiesta como un mecanismo de identificación para estos migrantes en el extranjero, marcando tanto sentidos de pertenencia dentro de su comunidad o colectividad como la habilitación de un sitio valorado en el actual contexto.

\section{Cambio de representación del Día de los Difuntos porteńo: del protagonismo nativo (desmarcado) hacia uno migrante (culturalmente marcado)}

A diferencia de la cosmovisión centroandina -y de otras en América Latina, África y Asia-, en la denominada como "occidental", en términos generales, la muerte es actualmente vista como una pérdida, experimentándose la ritualidad fúnebre con dolor, angustia e instrospección; sentimientos asociados al purgatorio cristiano (Fernández y Michel, 2014). Se trata de una celebración silenciosa y privada, en la que las personas se visten de negro y suelen hacer un panegírico del difunto. "La muerte implica una profunda interrupción, donde ya desde el siglo XII existe la idea de Juicio Final" (Hidalgo, 2011, p. 21).

Con la secularización de la sociedad occidental a lo largo del siglo XX, este rito fue perdiendo hegemonía. Hoy su masividad es percibida como un indicio de preeminencia que se asume como propio de lo amerindio o mestizo; índice que en varios países latinoamericanos fue incorporado como parte del discurso etnonacional. En el caso de Buenos Aires, como de otras ciudades de fuerte presencia europea, esto no siempre fue así.

Paralelamente a la desmasificación del rito local del Día de los Difuntos, principalmente en el cementerio de Chacarita, comienzan a masificarse los flujos migratorios desde NOA y Bolivia, que serán, justamente, los que reactivarán el festejo en Buenos Aires.

La masividad actual adquiere otras apreciaciones en el imaginario porteńo, justamente, porque es protagonizada por migrantes de los Andes centrales y sus descendientes: los nuevos responsables de este festejo en la urbe. Un ejemplo de este "traspaso" lo grafica una nota del 2013. Esta coloca una fotografía de la celebración en Flores, mencionando que se trata de "una conmemoración ancestral de la cultura boliviana" (El festejo del Día de los Muertos en Argentina, 2013, septiembre 3). Además, la aparición de un reportaje en el Canal Telefé por primera vez en 2015 (Barili, 2016) denota la relevancia que ha adquirido esta tradición para la ciudad y la asociación a su "origen boliviano" por parte del imaginario social local.

Este cambio en la significación de lo masivo -entre las multitudes que asistían antaño al camposanto y las que se congregan en la actualidad- adquiere la importancia desigual de los cementerios en estas concurrencias. Mientras la sociedad porteña asistía masivamente al cementerio de Chacarita, los nuevos usuarios del espacio concurren, mayoritariamente, al de Flores. La masividad cobra así una significación implícita diferencial, en la cual la concurrencia actual está asociada a los sectores populares de la ciudad. Por otra parte, los habitus corporales frente a las tumbas también son interpretados hegemónicamente a partir de ciertas economías de valor y distribuciones desiguales de legitimidad. La celebración "porteńa occidental" dispone los cuerpos para expresar una carencia de ambiente festivo: no suele haber música y si la hubiese, es tenue y funeraria, así como tampoco comida y bebida (estas están reservadas al velorio). La nueva masividad, al expresar sus sentimientos colectivos en un ambiente festivo, suele ser marcada culturalmente desde el exotismo, 
a diferencia del comportamiento anterior, el cual es un uso desmarcado del cementerio.

En las culturas de los Andes centrales "se concibe la muerte como un tránsito a otro plano de existencia, estando ésta integrada al sistema sociocultural" (Thomas, 1993, p. 114). El fallecimiento no implica dolor para los allegados al muerto, sino que estos esperan recibirlo con alegría. Se trata de tiempos y espacios de sentido vital y festivo antes que solemnes, los que definen pasos fundamentales en la vida de sus integrantes. Como explicita Vargas:

En el idioma aymara no existe el término para morir. Los difuntos no se fueron, retornan sus almas y están presentes [...] la muerte es entendida como un paso natural donde se conjuga el valor de dualidad (muerte vida) y de reciprocidad (ayni) entre vivos y muertos, donde la entrega de víveres y la celebración hacia el difunto devolverán prosperidad y fortuna a los vivos. En su contexto oriundo, esta reciprocidad es traducida en términos de bonanza en la cosecha. En el contexto urbano, y aun más en el trasnacional, esta ritualidad, al igual que otras, se manifiesta a partir de los nuevos tejidos sociales que se construyen. Durante la celebración, las familias se relacionan entre sí recreando prácticas y tradiciones "litúrgicas - comunitarias - funerarias", donde se ejerce una forma de ayni aymara-quechua en relación a los difuntos (Vargas, 2005, p. 11).

Según este testimonio, la relación de los migrantes y sus hijos y nietos con la fiesta es ejercida a partir del intercambio. Es justamente la apropiación por personas de los Andes centrales, aunque de diferentes identidades -rurales, urbanos, mestizos, aymara, kolla, quechua, de Cochabamba, La Paz o Jujuy-, la que permite ejercer "entre todos" una reciprocidad basada en la posibilidad de generar un territorio que antes no existía. Como plantea Giménez (2001), la desterritorialización física experimentada por estos migrantes no implica su desterritorialización simbólica, sino justamente la construcción de un nuevo territorio (Figura 14).

El mismo Vargas (2014), casi a diez años de haber escrito el párrafo arriba citado, me confirmaba: "En el cementerio de Flores se ve un mix de costumbres regionales. Aunque haya un cochabambino o un jujeño que llegó hace cuarenta años o un paceño hace quince, están compartiendo el mismo territorio y esos los constituye en comunidad" (Entrevista a Jorge Vargas, 2014).

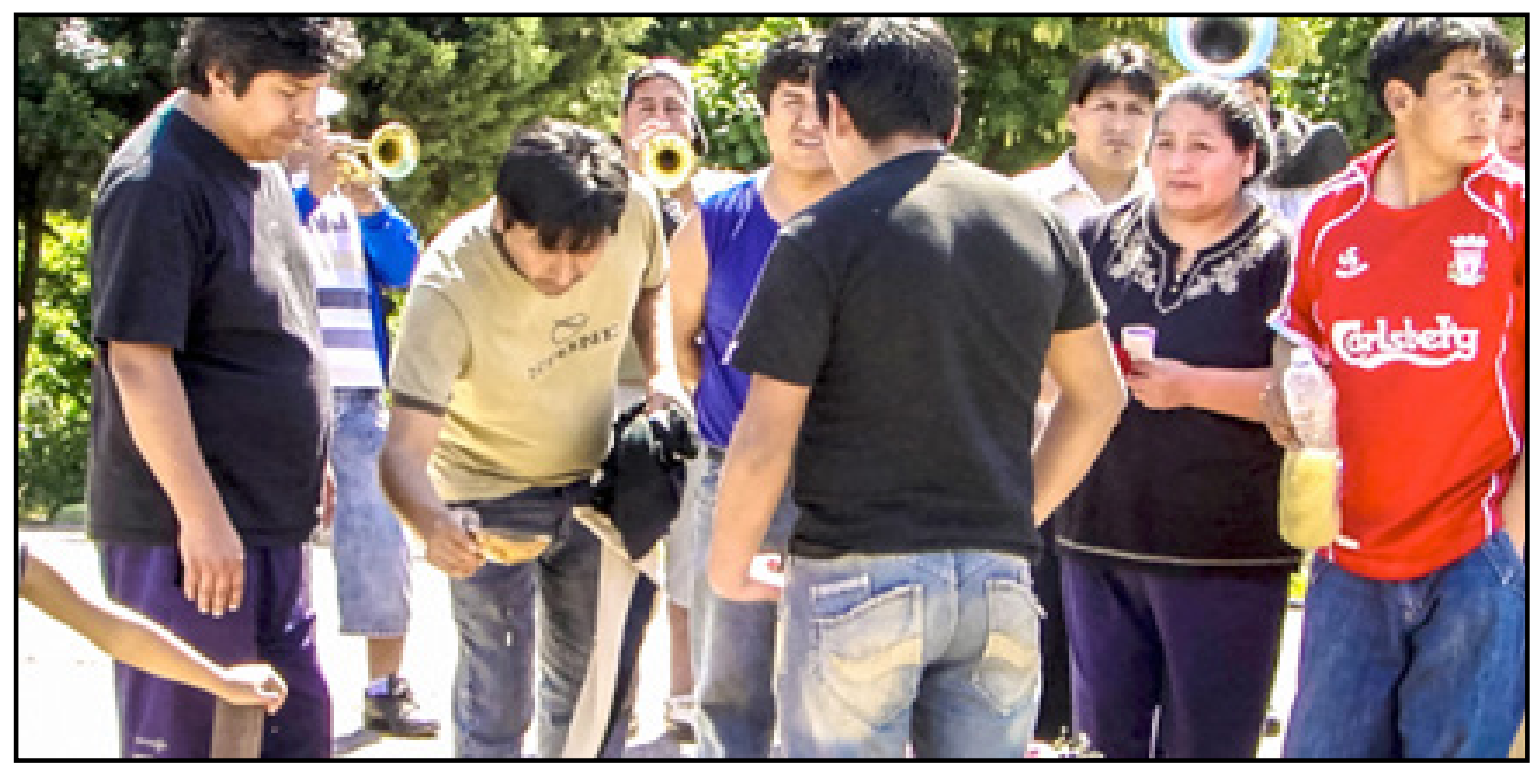

Figura 14. Ch'allando al muerto. Registro propio: 1 de noviembre de 2010. Buenos Aires, Argentina. 
Así, él explica de qué modo se negocian las prácticas y cómo de estos acuerdos surgen otras nuevas.

Me acuerdo una vez una mujer discutía con Juan José, un cochabambino: -No, pero allá se hace asi [...]. Luego de rozar un poco llegaron a acuerdo. Origenes diferentes que aqui comparten una misma práctica y tratan de imponer lo que ellos conocian, lo que lleva a generar una forma diferente producto de esas diferencias. Más elementos que se van incorporando de acá. Acá en una mesa de difunto aparece el mate. Otro ejemplo, es en Villegas, en San Justo donde hay muchos argentinos que están recreando la práctica, en vez de chicha llevan vino, asadito [...] son provincianos, chaqueños, tucumanos, son casi el mismo origen (Entrevista a Jorge Vargas, 2014).

Según estos testimonios, la lógica y, finalmente, el logro de esta festividad se explica por el relacionamiento entre personas de una misma macroárea con tiempos de arribo y territorios diferenciados, basado en un vínculo y una construcción respecto a su condición y rol como migrantes. Los ítems y formas de la producción de la fiesta son negociados, justamente, entre esas diferencias. Este territorio, además, genera propuestas novedosas a través de la incorporación de nuevos usos culturales. En síntesis, la consolidación de este festejo por parte de migrantes internacionales lleva a migrantes internos a recrear su memoria social, generando el desarrollo de prácticas familiares o comunitarias que, en muchos casos, habían sido abandonadas. La Figura 15 da cuenta de cómo estos migrantes junto a sus hijos y nietos representan dichos procesos en sus periódicos locales.

\section{Conclusiones. Las negociaciones del "ser-estar juntos" con los muertos del cementerio de Flores}

Aunque en un tiempo más acotado y negociando formas de la preparación y producción de la fiesta a partir de las experiencias de su origen, los migrantes centroandinos de Buenos Aires - en la mayoría de los casos acompańados por sus herederos porte-

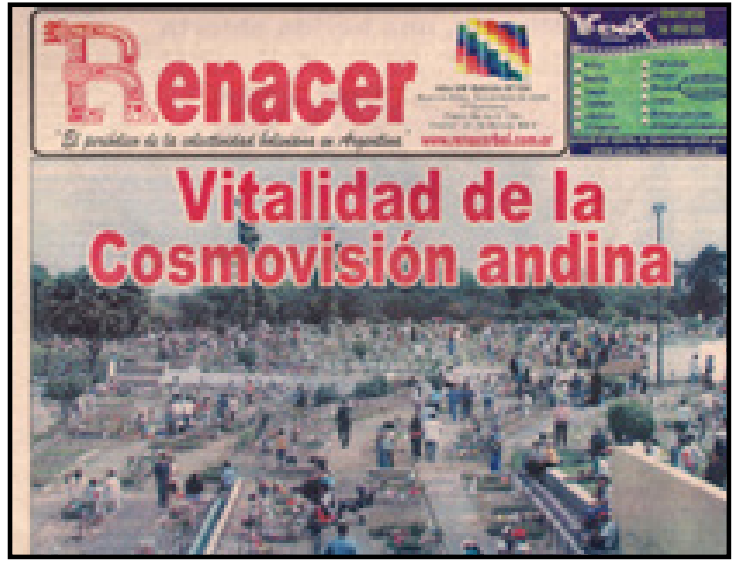

Figura 15. Vitalidad de la cosmovisión andina. Registro propio: 1 de noviembre de 2010. Buenos Aires, Argentina.

ños- (re)producen el culto a los muertos y lo llevan a cabo en forma masiva y comunitaria desde, aproximadamente, dos décadas y media en el cementerio de Flores. Migran a Buenos Aires, aquí mueren y siguen perteneciendo a su comunidad aymara, kolla o quechua.

Según mis experiencias etnográficas y la bibliografía consultada, considero que los sentidos locales tienen que ver con una mixtura entre el recuerdo de los más memoriosos, las limitaciones de llevar a cabo el festejo en otro lugar: un día no feriado, con distancias enormes de movilidad, limitaciones temporales por la hora de cierre del cementerio y malos tratos por parte de funcionarios; así como el cuestionamiento en relación a enterrar al muerto "aquí o mandarlo para alla”.

Este rito constituye la resignificación de una de las festividades agrocosmogónicas más importante de los Andes centrales, la cual, también resignificada en el contexto urbano, goza de un espacio relevante. Su concreción es producto de flujos migratorios diversos que generan dinámicas relacionales $\mathrm{y}$ de comunalización entre los vivos (presente) y los muertos (pasado) a través de la memoria social de los migrantes, adquiriendo renovadas significaciones simbólicas.

Actualmente, tanto los vivos como los muertos son mayoritariamente provenientes de los Andes centrales, principalmente del occidente y centro de 
Bolivia. Esta presencia denota, por una parte, una relevante capacidad de apropiación pública de la urbe $y$, por otra, una migración antigua que hace tiempo comenzó a enterrar a sus muertos en "suelo migratorio".

La celebración de los difuntos en el cementerio de Flores ejercita la convivencia comunitaria mediante la revalorización de los valores centroandinos, resaltando la importancia vital que tiene la forma en que este determinado colectivo de migrantes y sus familiares - muchos ya nacidos "aquî"- reconstruye y resignifica las costumbres culturales de sus regiones de origen mediante una de las más relevantes apropiaciones amerindias de un espacio público en esta metrópolis. Ciertos hechos concretos de estas prácticas ceremoniales y rituales demuestran la consolidación de relaciones como el compadrazgo/padrinazgo, el ayni y el compromiso colectivo. A su vez, constatan el hecho de que morir no rompe los vínculos comunitarios, y que el muerto sigue perteneciendo a la familia y a la comunidad, ayudándola y protegiéndola.

Asimismo, a partir de las experiencias de distintas familias, comprendo que la decisión de armar una mesa en nombre de algún ser querido es una opción que puede emerger motivada por los afectos, las memorias heredadas y las relaciones de vecindad en el nuevo sitio de habitación. Finalmente, entiendo que en destino el encuentro entre personas que no se conocen en el cementerio entrama también lazos comunes de pertenencia, a partir de los modos compartidos de usar el territorio festivamente, además de un lugar de vinculación entre muertos y vivos presentes.

Los hábitos que construyen la liminalidad del muerto, las formas que adquieren el festejo privado y el público, y los usos locales de los elementos necesarios (alimentos, adornos, íconos) guardan una relación directa con los Andes centrales.

Las prácticas que constituyen el ritual de los difuntos son sentidas como propias y heredadas (formas amerindias ancestrales), aunque su fuerza significativa e importancia en la cotidianeidad de las personas también es producto de las resignificaciones que estas adquieren a través de cruces de movilidades que constituyen el espacio migratorio urbano. En este contexto, los mecanismos relacionales entre vivos y muertos permiten el potenciamiento de una memoria social comunitaria que vincula de forma afectiva el presente con el pasado, generando comunalización en las trayectorias migratorias de quienes están vivos y de quienes ya no lo están. Es a partir de estos viajes y los respectivos retornos de los muertos, en los que se construye territorialidad, produciéndose -esta vez en un nuevo lugar- novedosos sentidos de pertenencia. Aun cuando no es fácil establecer cómo opera para el caso de los migrantes la forma de duelo escalonado propia del culto centroandino, nos revela de qué modo la idea de territorialidad -comprendida como espacio de reproducción afectiva y de pertenencia- está siendo redefinida.

\section{Agradecimientos}

El autor agradece al Consejo Nacional de Investigaciones Científicas y Técnicas de Argentina (CONICET) que financió la investigación que dio origen al presente artículo a través de su Programa de Becas Doctorales.

\section{Referencias citadas}

Aláez García, A. (2001). Duelo andino: sabiduría y elaboración de la muerte en los rituales mortuorios. Chungara. Revista de Antropología Chilena, 33(2), 173-178.

Albó, X. (1974). Reciprocidad complementaria, una categoría mental andina. Cochabamba: Departamento de Lingüística del centro Pedagógico y Cultural Portales

Barili, R. (Prod.). (2016). Día de los Muertos: cita en el cementerio. Telefé noticias [programa de televisión]. Buenos Aires: Telefé.

Barley, N. (2000). Bailando sobre la tumba. Barcelona: Anagrama.

Bastien, J. (1996). La Montaña del Cóndor: Metáfora y Ritual en un Ayllu Andino. La Paz: Hisbol.

Bauman, R. \& Briggs, C. (1990). Poetics and Performance as Critical Perspectives on Language and Social Life. Annual Review of Anthropology, 19, 59-88. 
Berg, H. V. D. (1989). La celebración de los difuntos entre los campesinos aimaras del Altiplano. Anthropos, 84, $155-175$.

Brow, J. (1990). Notas sobre comunidad, Hegemonía y los usos del pasado. Austin: Universidad de Texas.

Canelo, B. (2006). Migrantes del área andina central y Estado porteño ante usos y representaciones étnicamente marcados de espacios públicos. Buenos Aires: CLACSO - ASDI.

Canelo, B. (2010). Políticas públicas y migración en perspectiva antropológica. El Gobierno de la Ciudad de Buenos Aires ante usos del Cementerio de Flores por migrantes bolivianos. Temas de Antropología y Migración, 0, $8-34$.

Canelo, B. (2013, diciembre). Día de los difuntos. ¿Qué tenés ahí? Revista Anfibia. Disponible en: http://www. revistaanfibia.com/ensayo/que-tenes-ahi/

Canelo, B. y Vargas, J. (2001). Derechos y espacio público. La gestión de la comunidad andina en el Cementerio de Flores, Ciudad de Buenos Aires. En Courtis, C. y Pacecca, M. I. (Comps.). Discriminaciones étnicas y nacionales. Un diagnóstico participativo (pp. 79-95). Buenos Aires: Editores del Puerto y ADC.

Carsten, J. (2000). Cultures of Relatedness. New Approaches to the Study of Kinship. Cambridge, MA: Cambridge University Press.

Clemente, S. (2011, 2 de noviembre). Día de los muertos. Un rito de otro siglo casi olvidado en la actualidad. Clarín. Recuperado de http://www.clarin.com/ciudades/Diamuertos-siglo-olvidado-actualidad_0_583741738.html

De Certeau, M. (1996). La invención de lo cotidiano. Artes de hacer. México: Universidad Iberoamericana.

El festejo del Día de los Muertos en Argentina. (2013, septiembre 3). Info Región. Recuperado de http://www. inforegion.com.ar/noticia/62460/el-festejo-del-dia-delos-muertos-en-argentina

Fernández, F. y Michel, F. (2014). Conmemorando a nuestros muertos. Festividades y ritualidades en el Día de Difuntos. Santiago: Ocho Libros.

Fernández, G. (1998). “Todos Santos”: “Todos Almas”. Andina, 16(1), 139-159.
Fernández, G. (2011). Ñatitas, "almas" y “condenados”. Trasiego de osamentas en los Andes, siglos XVI-XXI. En Izquierdo Benito, R. y Martínez Gil, F. (Coords.). Religión y heterodoxias en el mundo hispánico: siglos XIV-XVIII (pp. 229-253). Castilla-La Mancha: Idolatrica.

Ferraro, E. (2004). Reciprocidad, don y deuda, formas y relaciones de intercambios en los Andes del Ecuador: la comunidad de Pesillo. Quito: Abya-Yala.

Garnier, J. (1904). The worship of the dead or the origin and nature of pagan idolatry and its bearing upon the early history of Egypt and Babylonia. London: Chapman \& Hall limited.

Giménez, G. (2001). Cultura, territorio y migraciones. Aproximaciones teóricas. Alteridades, 11(22), 5-14.

Guaman Poma de Ayala, F. (1980 [1615]). El primer nueva corónica y buen gobierno. México: Siglo XXI Editores.

Hidalgo, C. (Comp.) (2011). Etnografias de la muerte. Rituales, desapariciones, VIH/sida y resignificación de la vida. Buenos Aires: Ciccus.

Kauffman, F. (2010). Ultratumba entre los antiguos peruanos. Lima: Runa Yachachiy.

López Austin, A. (1999). Misterios de la vida y de la muerte. Arqueología mexicana, VII(40), 4-10.

Machicao Arauco, D. (2009). La música en la fiesta de Todos Santos: las nuevas prácticas y representaciones musicales en la despedida de las almas en Ovejuyo (Tesis de Licenciatura en Antropología y Arqueología). Universidad Mayor de San Andrés, La Paz, Bolivia.

Marcus, G. E. (1995). Ethnography in/of the world system: The emergence of multi-sited ethnography. Annual review of anthropology, 24(1), 95-117.

Mardones, P., García Recoaro, N., y Mamani, G. (Dir.) (2012). Tantawawas. Memoria del Indoamericano. [Documental]. Argentina: Alpaca Producciones, Colectivo 7 y Periódico Renacer.

Mardones, P. (2016). Buenos Aires Jacha Marka. Migrantes aymaras y quechuas en Buenos Aires. En los umbrales de un nuevo pachakutik (Tesis de Doctorado en Antropología). Universidad de Buenos Aires, Buenos Aires, Argentina. 
Massey, D. (1992). El espacio-tiempo, la ciencia y la relación entre la geografía física y la geografía humana. Cambridge, UK: Transactions of the Institute of British Geographers.

Milla, C. (1983). Génesis de la cultura andina. Lima: Fondo Editorial C.A.P.

Pratt, M. L. (1992). Imperial Eyes: Travel Writing and Transculturation. New York: Routledge.

Rivera Cusicanqui, S. (2010). Principio Potosí reverso. Otra mirada a la totalidad. Madrid: Museo Nacional Centro de Arte Reina Sofía.

Rogers, N. (2002). Halloween: From Pagan Ritual to Party Night. New York: Oxford University press.

Rostworowski Tovar de Diez Canseco, M. (1988). Historia del Tahuantinsuyo. Lima: Instituto de Estudios Peruanos.

Saignes, T. (1993). Borrachera y Memoria: La experiencia de lo sagrado en los Andes. Lima: Instituto Francés de Estudios Andinos.

Salomon, F. (1982). Andean Ethnology in the 1970s: A Retrospective. Latin American Research Review, 17(2), $75-$ 128.

Thomas, L. V. (1993). Antropología de la muerte. Barcelona: Paidós.

Urioste, M. (2004). Bolivia: de la recuperación democrática de 1982 a la agonía de los partidos y el nuevo protagonismo de las FFAA. Osal, 13, 153-163.
Van Gennep, A. (1960 [1909]). The Rites of Passage. Londres: The University of Chicago Press.

Vargas, J. (2005, noviembre). Ritual andino en el Cementerio de Flores. Renacer, VII(103), 14-16.

\section{Referencias primarias}

Cabrera, Carla (2 de noviembre, 2010). Notas de diario de campo. Buenos Aires.

Camacho, Ruth (13 de mayo, 2013). Notas de diario de campo. São Paulo.

Choque, Cafdey (4 de octubre, 2009). Notas de diario de campo. Buenos Aires.

Choque, Joselino (2 de noviembre, 2009). Notas de diario de campo. Buenos Aires.

Cortés, Gervasio (2 de noviembre, 2009). Notas de diario de campo. Buenos Aires.

Oviedo, Elizabeth (7 de julio, 2011). Notas de diario de campo. Buenos Aires.

Remonte, Lidia ( 6 de agosto, 2010). Notas de diario de campo. Buenos Aires.

Vargas, Jorge (14 de agosto, 2014). Notas de diario de campo. Buenos Aires. 